\title{
Why Do Workers with Disabilities Earn Less? Occupational Job Requirements and Disability Discrimination
}

\author{
Douglas Kruse $^{1}$ \\ Rutgers University \\ Lisa Schur ${ }^{2}$ \\ Rutgers University \\ Sean Rogers ${ }^{3}$ \\ Cornell University \\ Mason Ameri ${ }^{4}$ \\ Rutgers University
}

June 18, 2017

\section{Acknowledgements}

This paper has benefited from useful comments by Marjorie Baldwin, Daniel Hamermesh and H. Stephen Kaye. This research was supported by the Rehabilitation Research and Training Center on Employment Policy and Measurement, Institute on Disability, University of New Hampshire, funded by the National Institute on Disability and Rehabilitation Research, U.S. Department of Education.

\footnotetext{
${ }^{1}$ Douglas L. Kruse, Human Resource Management (HRM) Labor Studies and Employment Relations (LSER), Rutgers University, 94 Rockafeller Road, Piscataway, NJ 08854. dkruse@smlr.rutgers.edu

2 Lisa A. Schur, Department of Labor Studies and Employment Relations, Rutgers University, 50 Labor Center Way, New Brunswick, NJ 08903. lschur@smlr.rutgers.edu

${ }^{3}$ Sean Rogers, Management and Organizations, SC Johnson College of Business, Cornell University, Statler Hall, Ithaca, NY 14853. sean.rogers@cornell.edu

${ }^{4}$ Mason Ameri, Management and Global Business, Rutgers Business School, 1 Washington Park, Newark, NJ 07102. mason.ameri@rutgers.edu
} 


\title{
Why Do Workers with Disabilities Earn Less? Occupational Job Requirements and Disability Discrimination
}

\begin{abstract}
We analyse competing explanations for the lower pay of employees with disabilities, using 2008-2014 data from the American Community Survey matched to O*Net data on occupational job requirements. The results indicate that only part of the disability pay gap is due to productivity-related job requirements. The remaining pay gap — experienced by employees whose impairments should not limit their productivity — reflects potential discrimination. The discrimination-related pay gaps appear to be smallest and possibly non-existent for women and men with hearing impairments, and largest for those with cognitive and mobility impairments. Overall the results indicate that discrimination is likely to remain an influence on the pay of many workers with disabilities.
\end{abstract}

Keywords: disability, discrimination, wage gaps, occupational ability requirements, job requirements 


\section{Introduction}

Employed people with disabilities earn less on average than employed people without disabilities. Their lower earnings contribute to their generally low levels of income and assets, and high poverty rates, both in the USA and around the world (OECD 2010; Schur et al. 2013; WHO/World Bank 2011). Many public policies have been designed to improve employment outcomes for people with disabilities (e.g. the 1990 Americans with Disabilities Act and the 1999 Ticket to Work and Work Incentives Improvement Act) and there is on-going policy debate on how to increase access to and maintenance of well paid jobs for people with disabilities around the world (e.g. Burkhauser and Daly 2011; OECD 2010; WHO/World Bank 2011).

Why people with disabilities receive lower average earnings is an important policy question. One potential explanation is that people with disabilities tend to have lower average levels of productivity, which both decreases their chances of being offered acceptable employment (since the offered wage is less likely to exceed the reservation wage) and decreases their earnings if employed (since their output will be lower). A competing explanation is that discrimination decreases their employment and earnings, operating through employer prejudice, statistical discrimination and/or employer power over a group with limited job mobility. A third potential explanation is that people with disabilities accept compensating wage differentials for favourable job characteristics such as flexibility. Existing evidence lends some support to both the productivity-based and discrimination explanations, based on comparing disabilities with different levels of stigma or comparing people who do and do not report work-limiting disabilities (Baldwin and Choe 2014a, 2014b; Baldwin and Johnson 2006; DeLeire 2001; Jones 2008; Jones et al. 2014). 
Here, we use a different approach from most past studies, by relating wage differentials to occupational job requirements. The methodology is based on the study of 'beauty and the labour market’ by Hamermesh and Biddle (1994). That study sought to identify discrimination against less attractive people by examining whether they are paid less only in occupations where good looks may be ‘productive’ (e.g. sales) or also in jobs where looks should not matter (e.g. jobs with no customer contact, such as stock clerk). In a similar manner, we examine whether workers with disabilities earn less only in jobs where their disabilities would be expected to limit productivity (e.g. a mobility impairment in a job where walking and climbing are important), or also in jobs where disability should be irrelevant (e.g. a mobility impairment in a desk job). To the extent that disability earnings gaps are confined to occupations where a particular disability limits productivity, the productivity-based explanation will be supported. If, however, wage differentials exist generally across all occupations (possibly in combination with greater differentials in occupations where discrimination limits productivity), this would support the idea that discrimination is at work.

Our study matches US data on disability and earnings from the American Community Survey (ACS) with data on occupational ability requirements from the O*Net database. While our results are based on US data, they may also shed light on disability pay gaps found around the world, in studies of Australia, Canada, Spain, and the UK (Schur et al. 2013: 65). Following the literature review in the next section, we describe the data and methodology, document the disability wage gaps, analyse the relationship of those wage gaps to occupational ability requirements and offer conclusions and implication for policy and research.

\section{Theory and prior literature}


Lower earnings of workers with disabilities have been documented in a number of studies

— see the reviews by Baldwin and Johnson (2006) and Jones (2008) along with subsequent studies. ${ }^{1}$ The earnings gaps exist both before and after controlling for education and other personal characteristics. ${ }^{2}$ The lower earnings appear not only in cross-sectional comparisons but also in longitudinal comparisons before and after disability onset among those who become reemployed (Campolieti and Krashinski 2006; Krueger and Kruse 1995).

One potential explanation for the lower earnings of people with disabilities is that they have lower levels of productivity than non-disabled persons due to differences in education, training and/or functional limitations. While a number of studies have controlled for educational levels and years of work experience (reflecting formal and informal training among other factors), it is possible that remaining unmeasured differences in skill levels or health limitations contribute to the pay disparities. These unmeasured differences can reflect job mismatch which can affect productivity and pay for workers both with and without disabilities, but mismatch may be more of an issue for workers with disabilities due to their functional limitations (e.g. for those in a good job match before disability onset who decide to stay in the job after onset despite growing mismatch). The effects of skill mismatch appear to be particularly acute for workers with disabilities, as found by Jones and Sloane (2010). Choe and Baldwin (2017) also find that mismatched workers with physical disabilities have lower job duration, wages and hours than their counterparts who have a better match. Whether the pay gap is due to skill mismatch or not, one study using 1984 and 1993 US data found that most but not all of the pay gap associated with a reported work limitation disability was tied to functional limitations that presumably limit productivity (DeLeire 2001), while a UK study concluded that only about half of the disability pay gap could be explained by productivity related characteristics (Kidd et al. 2000), although 
another UK study concluded that productivity differences accounted for the full employment gap between people with and without disabilities (Jones 2006).

A second potential explanation for the low wages of employees with disabilities is discrimination. Some support for Becker’s taste-based model of discrimination comes from studies finding lower wages for people whose disabilities have lower 'social acceptability' rankings after controlling for productive characteristics including education and labour market experience (Baldwin and Johnson 2006). Statistical discrimination may be at work as employers may believe, rightly or wrongly, that people with disabilities are less productive on average, and make individual employment decisions based on this belief. The employer power/monopsony model may also be relevant, if people with disabilities face higher costs in switching jobs (due, e.g. to transportation problems or difficulties attaining accommodations) and the lower risk of turnover allows their current employers to underpay them (although one survey found people with disabilities were not more likely than those without disabilities to say they would have difficulty in finding a similar job at another organization) (Schur et al. 2017).

The prejudice and statistical models of discrimination are given some support by psychological studies showing that supervisor and co-worker attitudes affect the workplace experiences of people with disabilities (Colella 1996, 2001; Colella et al. 1998; Marti and Blanck 2000; Ren et al. 2008). In addition, employer surveys show that substantial portions of employers cite co-worker, supervisor and customer attitudes as challenges in hiring people with disabilities (Bruy`ere 2000, Dixon et al. 2003; Domzal et al. 2008; Kaye et al. 2011), and interviews with corporate executives revealed that 'most employers hold stereotypical beliefs not consistent with research evidence' (Lengnick-Hall et al. 2008: 255). In field experiments, employers were less likely to respond positively to job applications from (fictitious) people with 
disabilities than to otherwise-identical applications that did not indicate disability (Ameri et al. 2017; Baert 2016; Ravaud et al. 1992).

A third potential explanation for the lower average pay of employees with disabilities is that it reflects a compensating wage differential for a desirable job characteristic, such as flexibility. This may be a factor in the lower pay among workers who received workplace accommodations as found in Canadian and UK studies (Gunderson and Hyatt 1996; Jones and Latreille 2010). This is unlikely to fully explain the pay gaps since employees with disabilities tend to express lower job satisfaction (Burke 1999; Jones 2016; Jones et al. 2014; McAfee and McNaughton 1997; Renaud 2002; Schur et al. 2009, 2017; Uppal 2005), and their satisfaction should not be lower if they are simply choosing to trade off one characteristic for another. Also, people with disabilities (both employed and non-employed) tend to express similar views as their counterparts without disabilities on the relative importance of a number of job characteristics (Ali et al. 2011; Schur et al. 2017).While lower-paying part-time or temporary jobs may help some people with disabilities accommodate concerns about time, effort and flexibility, workers with disabilities continue to have lower pay and benefits when looking just at full-time nontemporary employees (Baldwin and Johnson 2006; Schur 2002).

While studies have looked at the possible effect of anti-discrimination legislation on employment levels among people with disabilities (e.g. Acemoglu and Angrist 2001; Button 2017; Jolls and Prescott 2004; Jones 2009; Kruse and Schur 2003), there has been much less focus on the effects of laws on pay disparities. Deleire (2001) did not find an initial effect of the Americans with Disabilities Act on disability pay disparities, while Jones et al. (2006) found that relative pay improved for work-limited men, but not for work-limited women, following the passage of the UK Disability Discrimination Act. 
In sum, earnings gaps between workers with and without disabilities have been well documented but not well explained. Several prior studies have attempted to separate the productivity-based and discriminatory components of the pay gap by making comparisons based on the social acceptability of different disabilities, or based on reports of functional limitations and a work-limiting disability. While they have yielded useful information, they must rely on untested assumptions about the relative productivity of people with disabilities.

Here, we use a different approach by analysing the occupational ability requirements of the jobs held by workers with disabilities, seeing if pay gaps are fully accounted for by functional limitations/impairments that limit productivity in a particular job. The only studies using a similar approach are by Baldwin and Choe (2014a, 2014b), who match disability and earnings data from the Survey of Income and Program Participation (SIPP) with job requirements data from the $\mathrm{O}^{*}$ Net database. Focusing on physical disabilities that cause a work limitation, Baldwin and Choe (2014a) examine how eight physical demands in the O*Net database moderate the relation between pay and disability status. They conclude that there are disability-related pay gaps that remain after accounting for any lower productivity from workers taking jobs where the disability conflicts with the job’s physical demands, with a greater remaining gap for men than for women. In a related study using the same dataset but focused on individuals with sensory impairments, they find that 'approximately one third (one tenth) of the male (female) disability-related wage differential is potentially attributed to discrimination' (Baldwin and Choe 2014b).

While we also use $\mathrm{O}^{*}$ Net data to help explain disability pay gaps, our approach is different from that of Baldwin and Choe in a fundamental way. A key difference is in the definition and measure of disability: they focus on explaining pay gaps tied to a reported 
limitation in the ability to work, while we focus on explaining pay gaps tied to four major impairments. Baldwin and Choe run separate wage equations for those who do and do not report work limitations, using impairments interacted with job requirements as predictors in both groups, and then decompose the gap between people who do and do not report work limitations. In contrast, we do not use a work limitation measure but instead directly examine the role of job requirements in explaining the pay gaps associated with four major impairments.

The work limitation measure has been used in much of the prior research on employment and wages, but it is not clear that this is the most appropriate measure of disability, particularly given the expanded definition of disability in the 2008 ADA Amendment Act (ADAAA) which was enacted at the beginning of our sample period. This Act continues the ADA's definition of disability as a physical or mental impairment that substantially limits one or more major life activities, but expands 'major life activities' to include many basic activities restricted by impairments, such as ‘seeing, hearing, eating, sleeping, walking, standing, lifting, bending, speaking, breathing, learning, reading, concentrating, thinking, [and] communicating'. In addition, 'major life activities’ now include ‘the operation of a major bodily function, including but not limited to, functions of the immune system, normal cell growth, digestive, bowel, bladder, neurological, brain, respiratory, circulatory, endocrine, and reproductive functions' (https://www.eeoc.gov/laws/statutes/adaaa.cfm). The ADAAA also directs the EEOC in its regulations to expand the definition of 'substantially limits' so that it means 'significantly restricted'. These changes mean that the ADA now covers a wide variety of impairments whether or not they restrict one's ability to work, giving support to the use of an impairmentbased measure of disability. 
There are other potential problems in interpreting results based on who reports a work limitation. One issue is that such reports may be influenced by the accessibility of the work environment and employer provision of accommodations, so that two workers with identical physical or mental impairments (both covered by ADAAA) in otherwise-similar jobs may respond differently to the work limitation question, complicating the interpretation of any estimated pay gap. A more basic problem is that the work disability measure is subject to biases from endogeneity, as employees with low wages or other poor employment outcomes may be more likely than others with the same objective impairments and medical conditions to report that they have a work disability as a way of justifying their poor outcomes. As noted by Kirchner, 'For if people with disabilities have better access to work and more of them actually hold jobs, especially good jobs, they would no longer answer that they are limited in or unable to work "due to their condition/disability"' (1996: 83). While some studies do not find evidence of reporting bias (Benitez-Silva et al. 2004; Cai 2009; Stern 1989), others find that non-employed people over-report work disability (Kapteyn et al. 2011; Kreider 1999; Kreider and Pepper 2007). The Kapteyn et al. study found such over-reporting in the US but not in Europe, suggesting differences in social norms around work, which is consistent with the finding that reports of work disability are strongly affected by reference groups (von Soest et al. 2011). Additional studies found that the work disability measure is more affected by endogeneity than are activity limitation measures (Oguzoglu 2012), and work disability reports are more affected by economic conditions than are measures of health disability (Benitez-Silva et al. 2010). While these studies focus on bias in reporting work disability based on one's employment status, it is very plausible that a similar bias may stem from one’s pay level, as workers who feel they are underpaid may be more likely to report a work disability to rationalize their low pay. This would 
cause the estimated disability pay gap to be overstated. Put another way, those who report a work disability may be less productive and have lower pay almost by definition since they see themselves as 'limited' in the work. The potential for endogeneity in the work disability measure makes it valuable to do analysis using alternative disability measures based on impairments and health conditions, which have been used in prior studies as exogenous instruments to adjust for the potential endogeneity of work disability.

Our approach therefore departs from prior research in part by using an impairment-based rather than work limitation measure of disability, which we argue may better capture the concept of disability as defined by the ADAAA, and also minimize concerns over endogeneity. We also employ a different econometric framework, and use post-ADAAA data from the 2008-2014ACS that provides a much larger and more recent sample than previous US studies based on data from 2004 or earlier. The SIPP data used by Baldwin and Choe has more detail on functional limitations, which they use to focus on physical disabilities (2014a) or sensory disabilities (2014b), while we cover four major categories of impairments in one analysis. They match these disabilities to 7 or 10 (for physical and sensory disabilities respectively) of the 52 O*Net ability requirements, while we use raters to assess the potential importance of each impairment for all 52 requirements. Apart from the substantive interest, our analysis using impairment-based measures allows for a methodological check on Baldwin and Choe's results based on the work disability measure. The use of different methods and datasets means that both approaches have the potential to produce valuable and complementary insights into the factors behind disability pay gaps.

\section{Data and method}


Data on wage differentials by disability status are obtained from the combined crosssections of the 2008-2014 ACS. The ACS implemented a new set of 6 disability questions in 2008 that distinguish among the broad categories of visual, hearing, cognitive, and mobility impairments, and two activity limitations (difficulty with self-care, and difficulty going outside alone). Following the Census Bureau method, people are defined as having a disability if they respond yes to one or more of the six questions (reproduced in Appendix A). ${ }^{3}$ We do not have information on the time of onset of disability, so cannot distinguish between congenital and acquired disabilities. We restrict our analysis to full-time full-year employees who are not in the military and have no income from self-employment, Social Security Disability Insurance or Supplemental Security Income. ${ }^{4}$ Within this sample of 2,549,129 women and 3,056,791 men, 4.3 per cent $(108,763)$ of women and 4.5 per cent $(137,233)$ of men are coded as having disabilities.

Wage differentials are established using a standard wage equation:

$$
\begin{aligned}
& L n\left(w_{i}\right)=a+b 1 \times \text { Disab }_{i m}+b 2 \times \text { Demog }_{i}+b 3 \times \text { Educ }_{i}+b 4 \times \\
& L M E_{x p i}+b 5 \times \text { year }_{t}+\text { state }_{s}+b 7 \times I M_{i}+e_{i}
\end{aligned}
$$

where $\ln \left(w_{\mathrm{i}}\right)=$ natural logarithm of hourly earnings

$$
\begin{aligned}
& \text { Disab }_{i m}=\text { dummy for any disability, or set of dummies for each type of impairment } m^{5} \\
& \text { Demog }_{i}=\text { dummies for black, Native American, Asian, other race and Hispanic } \\
& E d u c_{i}=\text { nine education dummies } \\
& L M E_{x p i}=58 \text { dummies representing years of potential labour market experience (age - } \\
& \text { education }-6) \\
& \text { Year = six-year dummies } \\
& \text { State = } 50 \text { state dummies (including D.C.) } \\
& I M_{i}=\text { Inverse Mill's ratio }
\end{aligned}
$$


$i$ subscript denotes individual

$m$ subscript denotes impairment

$t$ subscript denotes year

$s$ subscript denotes state

Hourly earnings is measured as annual earnings divided by 52 weeks divided by average hours worked per week. ${ }^{6}$ The inverse Mill's ratio to adjust for selection into full-time full-year employment is based on the Heckman procedure; results of the employment probit are not presented but are available on request. ${ }^{7}$

We focus on coefficients of the four impairment measures, representing the pay difference between someone with a given impairment and someone with no impairment or activity limitation. This is likely to capture people who are covered by the ADAAA definition of disability as discussed earlier. We recognize that these measures may be over-inclusive of those covered by the ADAAA, as a person may report an impairment that does not significantly restrict his or her activities. To the extent that this happens, such mismeasurement will bias our estimated disability pay gaps towards zero. We also explored results from interacting each impairment with the two activity limitation measures, which basically divides people into those with more severe and less severe disabilities. These results (not reported but available) showed few significant differences across these two groups, indicating that these activity limitation measures do not appear to be picking up productivity differences among those who are employed.

To examine within-occupation wage gaps, equation (2) adds occupational dummies:

$$
\begin{aligned}
& L n\left(w_{i}\right)=a+b 1 \times \text { Disab }_{i m}+b 2 \times \text { Demog }_{i}+b 3 \times E d u c_{i}+b 4 \times \\
& L M E_{x p i}+b 5 \times \text { year }_{i}+b 6 \times \text { state }_{s}+b 7 \times I M_{i}+b 8 \times O c c j+e_{i}
\end{aligned}
$$


Data on occupational ability requirements come from the federal government's $\mathrm{O}$ *Net database, version 17. Each occupation receives two scores for each of 52 abilities, one score representing the rated importance of that ability for that occupation on a 1 to 5 scale ('not important' to 'extremely important'), and the second score representing the level of the ability required on a 1 to 7 scale (with a zero assigned if the ability was rated 'not important' on the first scale). Appendix B provides a listing of the 52 occupational ability requirements, and Appendix C provides an example of the scoring for one of the abilities, 'arm-hand steadiness'. The ACS and $\mathrm{O}$ Net databases were merged using the SOC occupational code that is common to both datasets. ${ }^{8}$ A total of 524 occupations are identified, covering all non-military jobs.

Following the basic method of Hamermesh and Biddle (1994), we examine the interaction of impairments and occupational ability requirements to establish whether the wage differentials associated with disability are fully explained by ability requirements that are likely to limit productivity for people with particular impairments. In order to do this, we need to map required abilities from $\mathrm{O} * \mathrm{Net}$ to impairments from ACS, estimating which of the $52 \mathrm{O}$ Net abilities will be limited for each of the four impairments measured in the ACS. ${ }^{9}$ We obtained such independent estimates from 13 raters among the research team and advanced students in a Master's in Occupational Rehabilitation program. The raters filled out a survey with their judgments on each combination of the 4 impairments and the 52 ability requirements, judging whether a particular impairment (a) definitely would not limit, (b) might limit or (c) definitely would limit one's ability to meet the occupational ability requirement. For example, all raters judged that a hearing impairment 'might' or 'definitely would' limit oral comprehension, and they all agreed that it would not limit manual dexterity. Where the raters did not agree, we 
measured the likelihood of limitation as the proportion of raters who said an impairment might or definitely would limit an ability. ${ }^{10}$

The rater's judgments were combined with the 52 ability requirements to create two types of scores for each occupation, measuring the likelihood that each of the four impairments will reduce one's productivity in that occupation. The two types of scores reflect different ways in which impairments may limit productivity, either by (a) limiting the overall collection of abilities required in an occupation or (b) limiting an essential ability required in an occupation. The first score, called 'Requirements index', is measured as the proportion of required abilities for an occupation that are likely to be limited by a given impairment, multiplied by the level of ability required and weighted by the importance of the ability required:

Requirements_index $_{j m}=\sum\left(\right.$ limitation $_{k m} \times$ importance $_{j k} \times$ level $\left._{j k}\right) /$

$$
\begin{aligned}
& \sum\left(\text { importance }_{j k}\right) \text {, summing over } k=1 \text { to } 52 \\
& \text { abilities, separately for each occupation } j \text { and } \\
& \text { impairment } m
\end{aligned}
$$

where Requirements_index $j_{j m}=$ index of how much impairment limits ability to fulfill job requirements for occupation $j$ and $m$ (hearing, visual, cognitive and mobility) Limitation $_{k m}=$ likelihood that impairment $\mathrm{m}$ will limit ability to fulfill ability requirement $k$ (0-1 scale based on mean of rater's judgments)

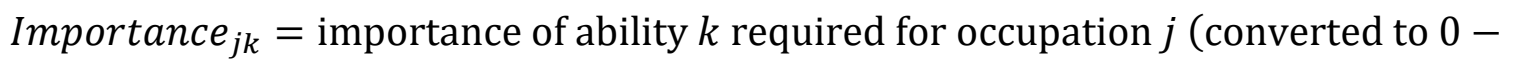
1 scale). Level $_{j k}=$ level of ability $k$ required for occupation $j$ (converted to 0-1 scale). ${ }^{11}$

This can be seen as a measure of how much an impairment will affect the basket of abilities needed in a particular occupation. When an occupation has a zero score, none of the important occupational abilities are likely to be limited by a given impairment, whereas a score 
of one indicates that all of the important occupational abilities are required at a high level and are likely to be limited by a given impairment. Because it reflects both importance and levels of required abilities, the index will increase with level of an ability required even as its importance stays constant.

The second type of score, called 'Very important requirement', reflects the= necessity of certain abilities for a job, where the need for certain abilities trumps all other requirements. For example, a bus driver must have good vision, and other abilities do not make up for a lack of good vision. This score is measured as:

Very_important_requirement $_{j m}=\max \left(\right.$ limitation $_{k m} \times$ vimportant $\left._{j k}\right)$

for $\mathrm{k}=1$ to 52 abilities, separately for each occupation $j$ and impairment $m$ where Very_important_requirement $t_{j m}=$ likelihood that impairment limits ability to fulfil very important job requirement for occupation $\mathrm{j}$ and impairment $\mathrm{m}$ (hearing, visual, cognitive and mobility);

Limitation $_{k m}=$ likelihood that impairment $m$ will limit ability to fulfil ability requirement k (0-1 scale based on mean of rater's judgements);

Vimportant $_{j k}=$ ability $k$ is 'very important' or 'extremely important' for occupation $j$ (dummy variable).

When an occupation has a score of zero on this measure, none of the raters thought that the impairment would limit one's ability to meet the 'very important' or 'extremely important' ability requirements in that job, whereas a score of one indicates that all of the raters thought the impairment would definitely limit the ability to meet one or more requirements that were rated as 'very important' or 'extremely important' in $\mathrm{O}$ *Net. 
To illustrate the scores with specific occupations, 'purchasing agents' have the minimum score of 0.012 for the Mobility requirements index score and a score of zero for the 'Very important mobility requirement' score, indicating that a mobility impairment is expected to limit productivity of purchasing agents only a very little or not at all. In contrast, 'dancers and choreographers' have the maximum score of 0.196 for the Mobility requirements index score (indicating that mobility represents about 20 per cent of the overall required skills for dancers and choreographers), and a score of one for 'Very important mobility requirement' (indicating that mobility is a critical and necessary skill for dancers and choreographers). As another example, 'postsecondary teachers' have a very low Mobility requirements index score (0.015) and a very high Cognitive requirements score (0.401), and (not surprisingly) a score of one for 'Very important cognitive requirement' indicating that some of the measured cognitive requirements are necessary for professors.

To test the sensitivity of the results, other tested scores included different weightings of the importance and level of abilities required (e.g. considering just importance and not level, or counting just proportion of important abilities limited), and different estimates of the rater's likelihoods that a particular impairment will impede the ability to perform an ability requirement. All of the tested occupation-level ability requirement scores were highly correlated and produced similar results.

The relation of job requirements to wage differentials is first assessed by adding the interaction of job requirements and impairment status to equation (2):

$$
\begin{aligned}
& L n\left(w_{i}\right)=a+b 1 \times \text { Disab }_{\text {im }}+b 2 \times \text { Demog }_{i}+b 3 \times \text { Educ }_{i}+b 4 \times L M E_{x p i}+b 5 \times \\
& \text { year }_{t}+b 6 \times \text { state }_{e}+b 7 \times I M_{i}+b 8 \times \text { Occ }_{j}+b 9 \times\left(\text { Disab }_{\text {im }} \times \text { Requirements }_{j m}\right)+e_{i}
\end{aligned}
$$


where Requirements $s_{j m}=$ Requirements_index $_{j m}$ or Very_important_requirement ${ }_{j m}$, defined above; other terms are defined above.

While it is standard to include the base effect with an interaction, in this case the base effect for the job requirements score, Requirements $s_{j m}$, is subsumed in the occupational dummies. The interaction coefficient $b 9$ tests whether the job requirements have a special effect on the earnings of people with disabilities, apart from their effect on worker earnings in general (captured in the occupation dummies). As described by Baldwin and Choe, the interaction term can be interpreted as the 'extent to which a worker's functional limitations affect productivity on the job' (2014b: 1396), and is expected to be negative. The b1 coefficient on the disability dummy variables then measures the residual wage gap after accounting for worker impairments that lower productivity.

Two other methods are also used to test the relationship between disability wage gaps and job requirements. The coefficients on the disability and job requirements variables in equations (1) and (2) may not be constant across the job requirement spectrum, which may lead to biased estimates of the key coefficients. The estimated disability coefficient may, for example, partially reflect low returns to education in occupations with low cognitive requirements, so that a specification assuming constant returns to education across all occupations is misleading. To examine this, rather than using the job requirements scores as predictors, we instead use them to divide the sample by occupation into five subsamples, and then run equation (2) for each subsample. By comparing the coefficients on the disability dummy variables across the subsamples, we can see whether the wage disparity for people with disabilities varies across occupations with different job requirement levels, after allowing all of the coefficients on control variables to vary freely in the five subsamples. 
Finally, to control any potential bias from within-occupation correlation of individual pay with unobserved job or personal characteristics, the analysis is run at the occupation level instead of the individual level, using the following equation:

$$
\operatorname{Disgap}_{j m}=a+b 1 \times \text { Jobreqs }_{j m}+e_{j}
$$

where Disgap $_{j m}=$ mean of residuals from equation (2) for those with impairment $m$ in occupation $j$, plus base coefficient on impairment m; Jobreqs $s_{j m}=$ Requirement_index or Very_important_requirement for occupation $j$ and impairment $m$, defined above.

The b1 term will measure productivity limitations at the occupational level — the degree to which the earnings of employees with disabilities are lower when their impairments limit their ability to fulfil the job requirements. The intercept ' $a$ ' term will measure whether there is a residual wage gap that may reflect discrimination after accounting for productivity limitations. This specification is run for each type of impairment using data on occupations where there are at least five employees with that impairment.

One important caveat is that the $\mathrm{O} *$ Net occupational ability requirements scores do not appear to take into account many accommodations that may enable someone to do a job. For example, 'near vision’ is rated as an important ability requirement in almost all occupations, even though people who are totally blind hold jobs in these occupations. ${ }^{12}$ For each of the impairments there is a wide range of accommodations that may allow the employee to perform jobs as productively as other employees. For our purposes of analysing wage differentials, this introduces error into our measures of job 'requirements', to which we will return. Related to this, workers may have devices that mitigate the effects of the impairment. While the vision question asks whether someone has 'serious difficulty seeing even when wearing glasses', the hearing 
question makes no reference to hearing aids and the mobility question makes no reference to mobility aids.

While the inverse Mill's ratio controls for selection into full-time full-year employment, it is possible that there are unobservable factors predicting selection into occupations - for example, workers with special aptitudes are more likely to select high-skill occupations. We are limited in accounting for this form of selection bias since we do not have variables that would clearly identify selection into an occupation and do not directly affect earnings. We do not believe this represents an important bias, however, since as will be seen the disability gap is changed only modestly by adding very detailed occupational fixed effects to the regressions. Therefore, any selection into occupations is likely to have only a small effect on the disability pay gaps examined here.

Four other potential forms of selection bias are likely to make our estimated pay gaps conservative, based on the types of workers with disabilities who remain employed full time full year. Workers who need time to recover from injuries, or to spend time in hospitals or rehabilitation, are likely to be lower earners and are excluded from our data because they are not full-time full-year employees. Second, mismatched workers have lower job duration and are more likely to be absent from our sample (Choe and Baldwin 2017). Third, workers who feel they have experienced discrimination are more likely to be discouraged and drop out, and therefore be absent from our sample. Fourth, workers can learn over time how to cope with their impairments, and may drop out if they do not cope well. This will lead to smaller estimated pay gaps since the workers who remain employed are more likely to be 'success stories'.

The measures of pay and disability are at the individual level while the measure of job requirements is at the occupation level. There is undoubtedly some variation in job requirements 
within occupations, and it is likely that individuals will select themselves into jobs that better match their abilities. To the extent that this happens, the estimated within-occupation disability pay gaps will be reduced, but from our results it is clear that such self-selection does not eliminate the pay gaps, so there is still a question of whether productivity or discrimination is responsible for the remaining gaps. While it would be ideal to have individual-level measures of job requirements, such data are not available in these or other datasets, and prior studies have also used occupation-level $\mathrm{O}$ Net data to proxy for individual job characteristics (e.g. Baldwin and Choe 2014a, 2014b; Hirsch and Schumacher 2012; Maxwell 2008).

All analyses are done separately for women and men, and are weighted using the weights supplied by the ACS. Unweighted analyses were also estimated to check for robustness of results (not reported but available) (Solon et al. 2015).

\section{Results}

\section{Disability Wage Gap}

Table 1 presents descriptive statistics, showing that women with disabilities earn on average 15.3 per cent less than women without disabilities (\$19.21 per hour compared to \$22.68), while men with disabilities earn 16.0 per cent less than men without disabilities (\$23.87 compared to \$28.41). The disability gap exists across the wage distribution but is slightly larger at higher levels of pay: the gap for women (men) is 12.5 per cent (9.8 per cent) at the lower quartile, 14.0 per cent (11.1 per cent) at the median and 14.5 per cent (15.5 per cent) at the upper quartile. Some of the disability wage gap may reflect differences in the occupational distribution, as Table 1 shows that employees with disabilities are under-represented in managerial and professional jobs, and overrepresented in service and blue-collar jobs. They are also less likely 
than employees without disabilities to have bachelor's or graduate degrees, which combined with their higher average age gives them higher average potential labour market experience. ${ }^{13}$

Among people with disabilities, the most common impairment is mobility among women (45.7 per cent) and hearing among men (43.2 per cent). People who did not list one of the four major impairments (visual, hearing, cognitive or mobility) but did report difficulty dressing or bathing, or going outside alone to do errands, are counted as having a disability and labelled as 'otherwise limited by daily activities', representing 4.6 per cent of women with disabilities and 3.6 per cent of men with disabilities.

Table 2 presents wage regressions based on equations (1) and (2). For women the log wage gap associated with disability in column 1 is -0.161 , implying a 14.9 per cent pay gap, and for men in column 5 it is -0.190 , implying a 17.3 per cent pay gap. ${ }^{14}$ When accounting for occupational fixed effects using 524 occupation dummies in columns 2 and 6, the estimated log wage gaps are reduced somewhat, to -0.123 for women and -0.172 for men, implying 11.6 per cent and 15.8 per cent gaps, respectively. ${ }^{15}$ As noted earlier, the modest changes when controlling for detailed occupational fixed effects lessen concerns about bias resulting from occupational selection. These average within-occupation differentials between employees with and without disabilities may of course vary by occupation, which we will explore using data on occupational ability requirements.

Table 2 also presents comparisons among the major impairments. The= largest pay gaps exist for employees with cognitive impairments ( -0.135 for women in column 4 , and -0.217 for men in column 8), and the smallest are for employees with hearing impairments $(-0.028$ for women and -0.038 for men). All of these estimates greatly exceed their standard errors, indicating statistical significance at the 0.001 level. Due to the large sample size almost all 
coefficients of interest in this paper are statistically significant, so we focus on the magnitudes to tell our story.

We probed the disability pay gap in three ways prior to examining the role of job requirements. These results are not presented here, but are available on request. First, we estimated quantile regressions to examine the effect of disability status on wages at the 10th, 25th, 50th, 75th and 90th percentiles of the wage distribution. The results show that the disability coefficients are very stable across the distribution, indicating that low-wage employees with disabilities experience roughly the same pay gap as high-wage employees with disabilities. Second, to examine the role of age and education, we ran equation (2) separately for three age groups (18-39, 40-54, 55-64) and for those with and without more than a high school education. The key results show different patterns for women and men: the disability wage gap is largest among women who are in the 40-54 age group and who have more than a high school degree, while the gap is equally large for men in the two older age groups and for those with and without post-high school education. For our purposes the key result is that the gap remains substantial and strongly significant among each of the age and education groups for both women and men. As a final check on the pay gap, we implemented a Blinder-Oaxaca decomposition that estimates separate equations for the disability and non-disability samples to examine the share of the disability pay gap that can be attributed to differences in coefficients ('unexplained') versus endowments ('explained'). The results show that 80 per cent or more of the disability pay gap remains unexplained, both before and after accounting for selection.

Effects of Job Requirements on Disability Wage Gap

We now turn to how occupational ability requirements influence these estimated disability pay gaps. Table 3 contains descriptive statistics on the job requirements scores. The 
Visual requirements index score, which reflects the relative importance of good vision in the basket of abilities needed for an occupation, ranges from 0.082 to 0.271 with a mean of 0.156 for women and 0.165 for men. Given that none of the scores are zero, this indicates that $\mathrm{O}$ Net raters ascribe at least some value to good vision in all of the occupations, as is also true for the hearing, cognition and mobility requirements scores. The 'Very important visual requirement' score, which reflects the necessity of a particular ability in an occupation, ranges from zero to one, indicating that good vision is not very important in some occupations but is necessary in others.

One way to validate these measures is to correlate them at the occupation level with the percentage of employees in that occupation who have a particular impairment. If these measures do reflect important abilities that enhance productivity in an occupation, there should be a negative correlation indicating fewer employees with impairments in occupations where those impairments conflict with the ability requirements. The correlations are in fact strongly negative for both women and men for visual, hearing and cognitive impairments, ranging from -0.383 to -0.767 , as shown in column 1 of Table 3 . For mobility impairments, however, the correlations are a positive 0.354 for women and 0.406 for men. This result may reflect a greater likelihood that workers in blue-collar jobs requiring mobility will develop mobility impairments (e.g. bad backs), but many are nonetheless able to remain in or return to those occupations. It may also reflect difficulty of such workers in transferring to jobs where their impairment is not a constraint. As will be seen, the wage patterns for workers with mobility impairments also do not conform to expectations, probably indicating a special selection story.

Using these occupational ability scores, the relation between disability pay gaps and occupational ability requirements is examined in three ways: first by interacting the occupational 
scores with the impairment variables in individual-level regressions (Table 4), second by running regressions on subsamples defined by the occupational scores (Figures 1(a)-4(b) and Tables 5), and finally by running occupation-level regressions of disability pay gaps on the occupational scores (Table 6).

Table 4 contains the results of regressions using equation (3) that include interactions with job requirements. As expected, almost all of the interaction coefficients show that earnings are lower for employees with visual, hearing and cognitive impairments as the job requirements for those abilities increase (rows 2, 3, 5, 6, 8 and 9). This likely reflects the lower productivity of employees as their impairments limit their ability to meet the job requirements in an occupation. The relationship is weak for visual impairments (rows 2 and 3), where none of the coefficients exceed the standard error, but is strong for several of the hearing and cognitive impairment interaction coefficients (rows 5, 6, 8 and 9). The mobility impairment results are puzzling, with the interaction coefficients being positive for the Mobility requirements index score (row 11), indicating that employees with mobility impairments are paid more in occupations where those impairments should be more limiting. This again suggests a special selection story, possibly that employees who are especially productive and incur mobility impairments are able to return to their occupations and continue to be paid well.

Is there a disability pay gap after accounting for productivity-limiting impairments? The answer appears to be yes for visual, cognitive, and mobility impairments, with more mixed results for hearing impairments. Columns 1 and 4 of Table 4 reproduce the base effects from the impairment dummy variables from Table 2, for comparison purposes. As the interactions are added, the base coefficient on visual impairment becomes smaller but remains negative for 
women in column 2 (-0.034), but remains of similar size when interactions are included for women in column $3(-0.059)$ and men in columns 5 and $6(-0.130,-0.090)$.

The story is more mixed for hearing impairments, where the hearing impairment pay gaps stay sizeable and statistically significant when controlling for the 'Very important hearing requirement' interaction (-0.021 in column 3 and -0.031 in column 6), but are not statistically significant when controlling for the hearing requirements index interaction (columns 2 and 5). The latter result indicates that the predicted hearing pay gap is close to zero when the hearing requirements are zero. A difficulty in interpreting this finding is that every occupation has a positive score for hearing requirements, so the base effect coefficient is essentially an out-ofsample prediction of what earnings would be if hearing requirements were zero.

The cognitive impairment pay gap decreases substantially for women but remains large for men when controlling for the cognitive requirements index interaction $(-0.028$ in column 2 and -0.182 in column 5) and remains sizeable when controlling for the 'very important cognitive requirement' interaction $(-0.117$ in column 3 and -0.207 in column 6).

Finally, the base coefficients on mobility impairments indicate that both women and men with mobility impairments have substantially lower earnings in occupations where the mobility impairment should not matter ( -0.121 and -0.108 for women, and -0.210 and -0.185 for men), which points towards discrimination, but the interpretation is muddied by their higher earnings in occupations where the impairment should be more limiting.

The story is more consistent when running the regressions separately by subsamples that are divided according to quintiles of job requirements. The key results are illustrated in Figures 1(a) to 4(b), based on regressions that are available on request. Employees earn less if they have an impairment, no matter the level of impairment-related job requirements in their occupation. 
The visual impairment pay gap varies little by job requirements quintile (Figure 1a,b), while the hearing impairment pay gap grows larger in the quintiles of occupation with higher hearing requirements (Figure 2a,b).

These results indicate that impairments seem to limit productivity more as hearing requirements increase, but the base coefficient is still negative for the lowest quintile indicating that people with hearing impairments receive lower earnings even at the lowest level of hearing requirements.

Similarly, the estimated cognitive impairment pay gap is largest in the top quintile of cognitive requirements (Figure 3a,b), but the gap remains strong in the lower quintiles. The mobility impairment pay gaps are smallest in the top quintile, but remain negative across the job requirements spectrum (Figure 4a,b), consistent with the results from Table 4.

This pattern is similar when occupations are divided by the 'Very important job requirement' scores instead of the job requirements index scores, as shown in Table 5. Because columns 1 and 3 restrict the sample to occupations where an impairment does not limit a very important job requirement, these specifications remove any potential correlation between the control variables and the 'Very important job requirement' score. The impairment-related pay gaps remain whether or not the impairment limits a very important job requirement.

As a final test, we present occupation-level regressions based on equation (4) in Table 6. The impairment-related pay gap is calculated from individual data for each occupation, and the occupation-level gap is then regressed on occupational job requirements. The first row of each panel contains the coefficient on the constant, which represents the estimated pay gap when impairments should not limit productivity (e.g. when the visual requirements index score is zero). Figures 5(a)-8(b) contain scatterplots of the results. The negative coefficients on the job 
requirements index (represented by negative slopes on the fitted lines in Figures 5(a) to 7(b)) indicate that impairment-related pay gaps tend to be larger in occupations where visual, hearing and cognitive impairments should be more limiting. The positive slopes in Figure 8(a) and (b) reproduce the puzzling result that mobility pay gaps are smaller in occupations where mobility impairments should be more limiting.

As can be seen in Table 6, almost all of the requirements-adjusted gaps are negative, indicating lower pay for people with that impairment even when the job requirement score equals zero. The results for hearing impairments are again mixed, showing pay gaps for both women and men when controlling for the 'Very important hearing requirement' score but not when controlling for the Hearing requirements index score. Overall, the pattern of results points to pay gaps that do not appear to be due to productivity limitations for women and men with visual, cognitive and mobility impairments, with mixed results for women and men with hearing impairments.

\section{Discussion and limitations}

The results taken together indicate that (a) job requirements are an important factor in the earnings of employees with disabilities and (b) productivity-limiting job requirements do not fully explain the lower earnings of employees with disabilities. The first conclusion is shown most clearly for visual, hearing and cognitive impairments, since employees with these impairments earn less in occupations where those skills are more important. Their lower earnings probably reflect lower productivity as their impairments limit the ability to fulfil job requirements (although we are not able to take account of accommodations, as discussed below). The pay gaps experienced by employees with mobility impairments defy expectations by 
growing smaller as mobility requirements increase, which may reflect highly experienced workers remaining in or returning to occupations with high mobility requirements after an injury that impairs mobility. In further probing we tested whether the patterns differed by age group (since we lack job tenure information but age is highly correlated with job tenure), and found similar patterns, indicating that any selection story is not confined to older workers. It is noteworthy that occupational mobility requirements are lower on average than visual, hearing and cognitive requirements (as shown in Table 3). When mobility requirements are low it may be easier to accommodate or avoid them altogether (e.g. by relying on another worker) and workers may compensate by stellar performance on other job requirements. The question of why employees with mobility impairments have smaller pay gaps in occupations where the impairments should be more limiting clearly deserves further research, ideally with data on tenure along with longitudinal data before and after a mobility impairment.

Do productivity limitations fully explain the lower pay of employees with disabilities? Most of our results indicate the answer is 'no', pointing to the possible role of discrimination. Figures 1(a) to 4(b) illustrate that employees with disabilities suffer wage penalties across the job requirements spectrum for each type of impairment. Taking the smallest gaps based on job requirements quintiles from Figures 1(a)-4(b) as measures of potential discrimination, it would appear that discrimination potentially lowers the pay of women (men) by 6.0 per cent (8.6 per cent) for visual impairments, 3.2 per cent (2.7 per cent) for hearing impairments, 9.9 per cent (16.9 per cent) for cognitive impairments and 7.7 per cent (22.3 per cent) for mobility impairments. Thanks in part to the large sample, all of these estimates substantially exceed their standard errors, indicating significance at the $\mathrm{p}<0.001$ level. Comparing to past estimates, the visual and hearing figures are roughly comparable to Baldwin and Choe’s (2014) unexplained 
pay gaps of 1.6 per cent for women and 8.4 per cent for men with sensory impairments (combining hearing, speech and visual), but the mobility figures are higher than their unexplained pay gaps of 2.7 per cent for women and 3.1 per cent for men with physical disabilities. Their lower estimates for physical disabilities, relative to our results for mobility impairments, may stem from their broader measure that includes limitations in any of a wide range of physical activities, not just walking or climbing stairs which reflect more severe disabilities.

The potential role of discrimination is weakest when considering hearing requirements. Several of the results using the job requirements index score indicate that hearing pay gaps for women and men would be close to zero in occupations where hearing skills are not required, which would suggest no discrimination exists. A strong caveat in drawing this conclusion, however, is that there are no occupations where $\mathrm{O}$ Net raters gave zero values on these job requirement scores, and the coefficients may be misleading in projecting the pay gap in such nonexistent occupations. Also, the results based on the second job requirements score (reflecting the necessity of certain skills in an occupation) indicate pay gaps that persist when these scores are zero, consistent with the idea that discrimination may play a role.

The gaps indicating potential discrimination may be overstated given the possibility that even the smallest gaps may reflect productivity limitations that are not captured by the variables considered here. For example, disabilities can be associated with increased fatigue or other health problems (independent of occupation demands measured here), which may be linked to higher rates of absenteeism or extended leaves that cause job skills to atrophy.

The results may also understate the role of discrimination to the extent that the $\mathrm{O}$ Net job requirements do not account for employee self-selection into jobs that better match their abilities, 
or take account of accommodations that enable employees with disabilities to perform jobs productively. For example, as noted above, the $\mathrm{O}$ *Net raters give ‘near vision’ at least some importance in all occupations, even though there are many totally blind people who are employed. Similarly, the $\mathrm{O}$ Net raters give at least some importance to auditory abilities in all of the occupations, even though there are many totally deaf people who are employed. If an employee with a disability has an adapted computer or other equipment that compensates for his or her limitations, he or she may be as productive as other employees, but still be underpaid due to discrimination. In this case the $\mathrm{O}^{*} \mathrm{Net}$ job requirements score may be unfairly attributing the lower pay to productivity limitations instead of discrimination.

\section{Conclusion}

Employees with disabilities experience substantial pay gaps, estimated here as $12-15$ per cent among women and 16-17 per cent among men who are full-time full-year workers. These pay gaps are not explained by differences in productivity-related skills gained through education or labour market experience. In this study we test whether the pay gaps may be explained by lower productivity due to limitations that an impairment places on one's ability to fulfil occupational job requirements. Using several methods, we find that disability pay gaps generally remain after accounting for job requirements, indicating that people with disabilities receive lower pay even when their specific impairments should not limit their productivity in an occupation.

These results support findings from prior literature in both the USA and UK that at least a portion of the lower earnings experienced by employees with disabilities is potentially attributable to discrimination (Baldwin and Choe 2014a, 2014b; Deleire 2001; Jones et al. 2006; 
Kidd et al. 2000). There may still be health-related reasons for the pay disparities, as discussed above, and it is important to address this possibility in future research. In addition, it will be valuable to examine the pay disparities over time, in particular following the 2008 ADA Amendments Act that expanded the number of US workers who are entitled to ADA protections against discrimination.

One important question is whether and how these results may apply outside the USA. From a research perspective, it would be valuable to see if similar or complementary methods can be used in other countries to examine pay gaps while controlling for likely productivity differentials, which may shed light on the effects of alternative policies. The US rights-based approach embodied in the ADA may not be the best way to improve the relative pay of workers with disabilities. The wide variety of approaches to improve employment outcomes for people with disabilities include not just anti-discrimination legislation but also employment quotas, employer incentives, employment supports, vocational rehabilitation and reform of disability income systems (OECD 2010: 78-84). It is likely that good lessons can be learned from studying employment outcomes across these policy regimes, ideally before and after the adoption or reform of policies within countries.

Another important development is that on-going improvements in computer technologies can provide particular benefits for workers with disabilities by helping compensate for functional limitations. Such technologies can increase their relative productivity at work and enable them to find jobs that better match their abilities (Krueger and Kruse 1995; Schur et al. 2013: 137-42). There may also be increased pressure to hire people with disabilities due to labour shortages as baby-boomers retire. While the results of this study indicate that disability discrimination still 
exists after 2008, it is valuable to study whether it may diminish over time as policy, technology and labour market trends increase the access of workers with disabilities to good-paying jobs. 


\section{Notes}

1. Bennett (2009), Schur et al. (2009, 2017), Baldwin and Choe (2014a, 2014b), Campolieti and Krashinski (2006).

2. Higher levels of education appear to narrow the pay gap between workers with and without disabilities, but a gap still remains (Hollenbeck and Kimmel 2008).

3. These six questions may miss a significant number of people who report work disabilities, as concluded by Burkhauser et al. (2014). To the extent that our 'nondisability’ sample includes people with disabilities, our disability wage gaps are likely to be underestimated. In addition, it should be noted that these six questions may identify a substantial number of people with 'invisible' disabilities that are not revealed to their employers. This may lead to a higher portion of the identified pay gaps being productivity-based (since discrimination has no direct role), which will understate the discrimination component that would be found using a work disability measure that is likely to include fewer invisible disabilities.

4. The full-time restriction is imposed to provide a cleaner test of the relation of wage differentials to disability, since part-time workers are paid less in general and workers with disabilities are overrepresented among part-time workers. The full-year restriction is imposed because hourly earnings can only be reliably calculated for full-year workers (since earnings are reported on an annual basis and the exact number of weeks worked is not recorded for part-year employees). Military employees are excluded because $\mathrm{O} * \mathrm{Net}$ has no information on their occupational ability requirements. The restriction to those with no self-employment income is imposed because hours worked per week is not separated by employment type for those who were both employees and self-employed. 
Those with SSDI or SSI income were excluded because of the well-known employment disincentives in those programs.

5. People can report more than one impairment. The equations with impairment dummies also include a dummy for those reporting no impairment but an activity limitation in dressing, bathing, or going outside alone (questions 5 and 6 in Appendix A).

6. Pay is adjusted for inflation to 2014 values, and values of less than $\$ 2.50$ or greater than $\$ 500$ per hour were trimmed.

7. For the Heckman procedure, the probit predicting employment uses the variables in equation (1) along with family size, total income of other family members, presence for children under age 6 and a dummy for living alone.

8. The ACS coding of SOC was updated in 2010 and 2012 so matches were done separately for ACS data in 2008-2009, 2010-2011 and 2012-2013.

9. We could not easily map the two activity limitation measures to ability requirements since the activity limitations could reflect a wide variety of different types of abilities.

10. We also tested limitation measures based on (a) the percentage of raters who said that an impairment would definitely limit an ability, (b) the mean of an index where $0=$ definitely would not limit ability, $0.5=$ might limit ability and $1=$ definitely would limit ability, and dummy variables reflecting whether (c) a majority said that an impairment might or would definitely limit an ability, (d) a majority said that an impairment would definitely limit an ability, (e) at least 75 per cent of raters said an impairment might or would definitely limit an ability and (f) at least 75 per cent of raters said an impairment would definitely limit an ability. The results were similar across the measures. 
11. The conversion for the importance measure was done by subtracting 1 from the $1-5$ scale and dividing by 4 , and for the level measure was done by dividing the $0-7$ scale (with 0 assigned when the ability is 'not important') by 7.

12. The combined 2002-2008 National Health Interview Surveys, conducted by the Centers for Disease Control, show that 40.7 percent of working-age people who are 'blind or unable to see at all' are employed, holding jobs in a wide range of occupations. (The top five are administrative support, management, sales, business and financial operations and production). We thank H. Stephen Kaye for these calculations.

13. This is measured as age minus years of schooling minus 6 . Actual labour market experience is not available in the ACS. The higher potential labor market experience of people with disabilities reflects both a higher average age and fewer years of schooling completed on average. Potential labour market experience is measured using year dummies rather than continuous terms to allow the wage path to be unconstrained by assumptions about the shape of the wage-experience distribution.

14. The estimated gap in $\ln$ (pay) without the selection correction is -0.106 for women in column 1 and -0.122 for men in column 5 . The widening of the pay gap when controlling for selection is consistent with the idea that people with disabilities often face extra employment barriers (e.g. transportation and accessibility problems), so that those who do not have high earnings potential will be discouraged from working. The employed sample of people with disabilities will consequently be skewed toward those with high earnings potential, reducing the estimated wage gap between employees with and without disabilities when no selection correction is used. 
15. The changes in the disability coefficients as occupational dummies are added are significant at the $\mathrm{p}<0.001$ level. 


\section{References}

Acemoglu, D. and Angrist, J. (2001). 'Consequences of employment protection? The case of the Americans with Disabilities Act'. Journal of Political Economy, 109 (5): 915-57.

Ali, M., Schur, L. and Blanck, P. (2011). 'What types of jobs do people with disabilities want?' Journal of Occupational Rehabilitation, 21 (2): 199-210.

Ameri, M., Schur, L., Adya, M., Bentley, S., McKay, P. and Kruse, D. (2017). 'The disability employment puzzle: a field experiment on employer hiring behavior’. ILR Review, https://doi.org/10.1177/0019793917717474.

Baert, S. (2016). 'Wage subsidies and hiring chances for the disabled: some causal evidence’. The European Journal of Health Economics, 17 (1): 71-86.

Baldwin, M. and Choe, C. (2014a). 'Re-examining the models used to estimate disability-related wage discrimination'. Applied Economics, 46 (12): 1393-408.

—and_—(2014b). 'Wage discrimination against workers with sensory disabilities'. Industrial Relations: A Journal of Economy and Society, 53 (1): 101-24.

_ and Johnson, W. (2006). 'A critical review of studies of discrimination against workers with disabilities’. In W. M. Rodgers III (ed.), Handbook on the Economics of Discrimination. Northampton, MA: Edgar Elgar Publishing, pp. 119-60.

Benitez-Silva, H., Buchinsky,M., Chan, H., Cheidvasser, S. and Rust, J. (2004). 'How large is the bias in self-reported disability?' Journal of Applied Econometrics, 19 (6): 649-70.

—_ Disney, R. and Jimenez-Martin, S. (2010). 'Disability, capacity for work and the business cycle: an international perspective’. Economic Policy, 25 (63): 483-536. 
Bennett, J. (2009). 'Disability and labor market outcomes in the United States: exploring the linkage between disability, education, and labor market earnings’. Masters Abstracts International, 47 (5), 2586.

Bruyere, S. (2000). Disability Employment Policies and Practices in Private and Federal Sector Organizations. Ithaca, NY: Cornell University, Program on Employment and Disability.

Burke, R. (1999). ‘Disability and women’s work experiences: an exploratory study’. International Journal of Sociology and Social Policy, 19 (12): 21-33.

Burkhauser, R. and Daly, M. (2011). The Declining Work and Welfare of People with Disabilities: What Went Wrong and a Policy for Change. Washington, DC: AEI Press.

—_ Houtenville, A. and Tennant, J. (2014). 'Capturing the elusive working-age population with disabilities'. Journal of Disability Policy Studies, 24 (4): 195-205.

Button, P. (2017). ‘Expanding employment discrimination protections for individuals with disabilities: evidence from California’. ILR Review, https://doi.org/10.1177/0019793917716633

Cai, L. (2009). 'Is self-reported disability status endogenous to labour force status?’ Applied Economics Letters, 16, 459-64.

Campolieti, M. and Krashinsky, H. (2006). 'Disabled workers and wage losses: some evidence from workers with occupational injuries'. Industrial and Labor Relations Review, 60 (1): $120-38$.

Choe, C. and Baldwin, M. (2017). 'Duration of disability job mismatch and employment outcomes’. Applied Economics, 49 (19): 1001-15. 
Colella, A. (1996). 'Organizational socialization of newcomers with disabilities: a framework for future research’. In G. R. Ferris (ed.), Research in Personnel and Human Resources Management. Greenwich, CT: JAI Press, pp. 351-417.

_ (2001). 'Coworker distributive fairness judgments of the workplace accommodation of employees with disabilities’. Academy of Management Review, 26 (1): 100-16.

— - DeNisi, A. and Varma, A. (1998). 'The impact of ratee’s disability on performance judgments and choice as partner: the role of disability-job fit stereotypes and interdependence of rewards'. Journal of Applied Psychology, 83 (1): 102-11.

DeLeire, T. (2001). 'Changes in wage discrimination against people with disabilities: 19841993’. Journal of Human Resources, 36 (1): 144-58.

Dixon, K., Kruse, D. and Van Horn, C. (2003). Restricted Access: A Survey of Employers About People with Disabilities and Lowering Barriers to Work. New Brunswick, NJ: Rutgers University, John J. Heldrich Center for Workforce Development.

Domzal,C., Houtenville,A. and Sharma, R. (2008). Survey of Employer Perspectives on the Employment of People with Disabilities: Technical Report. McLean, VA: CESSI.

Gunderson, M. and Hyatt, D. (1996). 'Do injured workers pay for reasonable accommodation?' Industrial and Labor Relations Review, 50 (1): 92-104.

Hamermesh, D. and Biddle, J. (1994). 'Beauty and the labor market'. American Economic Review, 84 (5): 1174-94.

Hirsch, B. and Schumacher, E. (2012). 'Underpaid or overpaid? Wage analysis for nurses using job and worker attributes'. Southern Economic Journal, 78 (4): 1096-119.

Hollenbeck, K. and Kimmel, J. (2008). 'Differences in the returns to education for males by disability status and age of disability onset’. Southern Economic Journal, 74 (3): 707-24. 
Jolls, C. and Prescott, J. (2004). 'Disaggregating Employment Protection: The Case of Disability Discrimination’. Working Paper 10740, National Bureau of Economic Research.

Jones, M. (2006). “Is there employment discrimination against the disabled?' Economics Letters, 92 (1): 32-7.

_ (2008). 'Disability and the labour market: a review of the empirical evidence'. Journal of Economic Studies, 35 (5-6): 405-24.

_ (2009). 'The employment effect of the Disability Discrimination Act: evidence from the health survey for England'. Labour, 23 (2): 349-69.

— (2016). 'Disability and perceptions of work and management'. British Journal of Industrial Relations, 54 (1): 83-113.

_ (2010). 'Disability and earnings: are employer characteristics important?’ Economics Letters, 106 (3): 191-94.

— $—$ - and Sloane, P. (2006). 'Disability, gender, and the British labour market'. Oxford Economic Papers, 58 (3): 407-49.

—_, Mavromaras, K., Sloane, P. and Wei, Z. (2014). 'Disability, job mismatch, earnings and job satisfaction in Australia'. Cambridge Journal of Economics, 38 (5): 1221-46.

_ and Sloane, P. (2010). 'Disability and skill mismatch'. Economic Record, 86: 101-14.

Kapteyn, A., Smith, J. and Van Soest, A. (2011). 'Work disability, work, and justification bias in Europe and the United States'. In D. Wise (ed.), Explorations in the Economics of Aging. Chicago, IL: University of Chicago Press, pp. 269-312.

Kaye, H.S., Jans, L. and Jones, E. (2011). 'Why don’t employers hire and retain workers with disabilities?' Journal of Occupational Rehabilitation, 21 (4): 526-36. 
Kidd,M., Sloane, P. and Ferko, I. (2000). 'Disability and the labour market: an analysis of British males’. Journal of Health Economics, 19 (6): 961-81.

Kirchner, C. (1996). 'Looking under the street lamp: inappropriate uses of measures just because they are there'. Journal of Disability Policy Studies, 7 (1): 77-90.

Kreider, B. (1999). 'Latent work disability and reporting bias'. Journal of Human Resources, 34 (4): 734-69.

— and Pepper, J. V. (2007). 'Disability and employment: reevaluating the evidence in light of reporting errors'. Journal of the American Statistical Association, 102 (478): 432-441.

Krueger, A. and Kruse, D. (1995). 'Labor Market Effects of Spinal Cord Injuries in the Dawn of the Computer Age’. National Bureau of Economic Research Working Paper No. 5302.

Kruse, D. and Schur, L. (2003). 'Employment of people with disabilities following the ADA'. Industrial Relations, 42 (1): 31-64.

Lengnick-Hall, M., Gaunt, P. and Kulkarni, M. (2008). 'Overlooked and underutilized: people with disabilities are an untapped human resource’. Human Resource Management, 47 (2): 255-73.

Marti, M. and Blanck, P. (2000). 'Attitudes, behavior, and the ADA'. In P. Blanck (ed.), Employment, Disability, and the Americans with Disabilities Act: Issues in Law, Public Policy, and Research, Evanston, IL: Northwestern University Press, pp. 356-84.

Maxwell, N. (2008). 'Wage differentials, skills, and institutions in low-skill jobs'. Industrial and Labor Relations Review, 61 (3): 394-409.

McAfee, J. and McNaughton, D. (1997). 'Transitional outcomes—job satisfaction of workers with disabilities, part one: general job satisfaction'. Journal of Vocational Rehabilitation, 8 (2): 135-42. 
OECD. (2010). Sickness, Disability, and Work: Breaking the Barriers. Paris: Organisation for Economic and Co-operation and Development.

Oguzoglu, U. (2012). 'Is there a better measure of self-assessed disability?’ Applied Economics Letters, 19 (14): 1335-8.

Ravaud, J., Madiot, B. and Ville, I. (1992). 'Discrimination towards disabled people seeking employment’. Social Science \& Medicine, 35 (8): 951-8.

Ren, L., Patezold, R. and Colella, A. (2008). 'A meta-analysis of experimental studies on the effects of disability on human resource judgments'. Human Resource Management Review, 18 (3): 191-203.

Renaud, S. (2002). 'Rethinking the union membership/job satisfaction relationship: some empirical evidence in Canada’. International Journal of Manpower 23 (2): 137-50.

Schur, L. (2002). 'Dead-end jobs or a path to economic well-being? The consequences of nonstandard work for people with disabilities'. Behavioral Sciences and the Law, 20: 60120.

—_, Kim, A., Han, K., Ameri, M., Adya, M., Blanck, P. and Kruse, D. (2017). 'Disability at Work: A Look Back and Forward’. Working Paper, Rutgers University, School of Management and Labor Relations.

— Kruse, D. and Blanck, P. (2013). People with Disabilities: Sidelined or Mainstreamed? Cambridge: Cambridge University Press.

$\ldots$ _ _ _ Blasi, J. and Blanck, P. (2009). 'Is disability disabling in all workplaces? Workplace disparities and corporate culture'. Industrial Relations, 48 (3): 381-410.

Solon, G., Haider, S.J. and Wooldrige, J.M. (2015). 'What are we weighting for?' Journal of Human Resources, 50 (2): 301-16. 
Stern, S. (1989). 'Measuring the effect of disability on labor force participation'. Journal of Human Resources, 24: 361-95.

Uppal, S. (2005). 'Disability, workplace characteristics and job satisfaction'. International Journal of Manpower, 26 (4): 336-49.

Van Soest, A., Andreyeva, T., Kapteyn, A. and Smith, J. (2011). 'Self-reported disability and reference groups'. In D. Wise (ed.), Investigations in the Economics of Aging. Chicago, IL: University of Chicago Press, pp. 237-64.

WHO/World Bank (2011). World Report on Disability. Geneva, Switzerland: World Health Organization and World Bank. 
Table 1. Descriptive Statistics

Hourly earnings

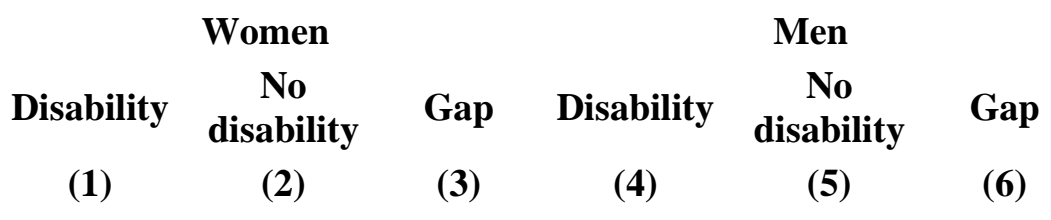

\begin{tabular}{|c|c|c|c|c|c|c|}
\hline Mean (std. dev.) & $\begin{array}{l}19.21 \\
(14.28)\end{array}$ & $\begin{array}{l}22.68 \\
(17.42)\end{array}$ & $\begin{array}{l}- \\
15.3 \% * *\end{array}$ & $\begin{array}{l}23.87 \\
(19.45)\end{array}$ & $\begin{array}{l}28.41 \\
(25.08)\end{array}$ & $-\overline{16.0 \% * *}$ \\
\hline Lower quartile & 10.98 & 12.55 & $-\overline{12.5 \% * *}$ & 12.87 & 14.28 & $-9.8 \% * *$ \\
\hline Median & 16.06 & 18.66 & $-\overline{14.0 \% * *}$ & 19.47 & 21.91 & - \\
\hline Upper quartile & 23.59 & 27.60 & $-\overline{14.5 \% * *}$ & 28.84 & 34.14 & $-\overline{15.5 \% * *}$ \\
\hline $\begin{array}{l}\text { Mean of ln(earnings) (std. } \\
\text { dev.) }\end{array}$ & $2.78(0.59)$ & $2.93(0.61)$ & $-\overline{13.9 \% * *}$ & $2.96(0.63)$ & $3.10(0.68)$ & $-\overline{13.0 \% * *}$ \\
\hline
\end{tabular}

Impairment type

$\begin{array}{lllll}\text { Visual impairment } & 0.219 & 0.000 & 0.206 & 0.000 \\ \text { Hearing impairment } & 0.239 & 0.000 & 0.432 & 0.000 \\ \text { Cognitive impairment } & 0.214 & 0.000 & 0.212 & 0.000 \\ \begin{array}{l}\text { Mobility impairment } \\ \begin{array}{l}\text { Otherwise limited in daily } \\ \text { activities }\end{array}\end{array} & 0.457 & 0.000 & 0.298 & 0.000 \\ \end{array}$

Occupation

Management

Mgt related

Professional

Service

Sales

Admin. support

Blue-collar

Race/ethnicity

White

Black

Native American

Asian

Other race

Hispanic

Education

No high school

Some high school

High school

$$
0.081
$$

0.054

0.227

0.194

0.089

0.262

0.093

0.727

0.168

0.013

0.028

0.064

0.127

0.032

0.063

0.232
0.105

0.072

0.280

0.147

0.090

0.237

0.069

0.739

0.139

0.007

0.057

0.057

0.136

0.020

0.035

0.201
$-0.024 * * 0.091$

$-0.018 * * 0.034$

$-0.053 * * 0.139$

$0.047 * * \quad 0.143$

$-0.002 \quad 0.081$

$0.026 * * \quad 0.084$

$0.024 * * \quad 0.428$

$-0.013 * * 0.802$

$0.029 * * \quad 0.095$

$0.006 * * \quad 0.011$

$-0.029 * * 0.027$

$0.006 * * \quad 0.064$

$-0.009 * * 0.135$

$0.012 * * \quad 0.046$

$0.027 * * \quad 0.085$

$0.031 * * \quad 0.272$
0.121

0.045

0.184

0.127

0.097

0.072

0.354

0.770

0.097

0.006

0.056

0.071

0.173

0.039

0.059

0.238

$-0.030^{* *}$
$-0.011^{* *}$
$-0.045^{* *}$
$0.016^{* *}$
$-0.016^{* *}$
$0.012^{* *}$
$0.074^{* *}$

$0.032 * *$

$-0.002$

$0.006 * *$

$-0.029 * *$

$-0.007 * *$

$-0.038 * *$

$0.006 * *$

$0.025 * *$

$0.034 * *$ 


\begin{tabular}{|c|c|c|c|c|c|c|}
\hline & \multicolumn{3}{|c|}{ Women } & \multicolumn{3}{|c|}{ Men } \\
\hline & Disability & $\begin{array}{c}\text { No } \\
\text { disability }\end{array}$ & Gap & Disability & $\begin{array}{c}\text { No } \\
\text { disability }\end{array}$ & Gap \\
\hline & (1) & (2) & (3) & (4) & (5) & (6) \\
\hline GED & 0.044 & 0.025 & $0.020 * *$ & 0.051 & 0.033 & $0.019 * *$ \\
\hline Some college, no degree & 0.281 & 0.235 & $0.046 * *$ & 0.258 & 0.218 & $0.040 * *$ \\
\hline Associate's & 0.111 & 0.109 & 0.002 & 0.086 & 0.081 & $0.004 * *$ \\
\hline Bachelor's & 0.153 & 0.240 & $-0.087 * *$ & 0.135 & 0.216 & $-0.081 * *$ \\
\hline Master's & 0.067 & 0.104 & $-0.036^{* *}$ & 0.049 & 0.079 & $-0.030 * *$ \\
\hline Professional degree & 0.011 & 0.019 & $-0.009 * *$ & 0.011 & 0.021 & $-0.010 * *$ \\
\hline Doctoral degree & 0.007 & 0.012 & $-0.005 * *$ & 0.009 & 0.015 & $-0.007 * *$ \\
\hline $\begin{array}{l}\text { Potential labour market } \\
\text { experiencea (std. dev.) }\end{array}$ & $\begin{array}{l}27.45 \\
(11.71)\end{array}$ & $\begin{array}{l}21.22 \\
(12.07)\end{array}$ & $6.24^{* *}$ & $\begin{array}{l}27.43 \\
(11.90)\end{array}$ & $\begin{array}{l}21.16 \\
(11.71)\end{array}$ & $6.27 * *$ \\
\hline Inverse Mill's ratio (std. dev.) & $\begin{array}{l}0.936 \\
(0.32)\end{array}$ & $\begin{array}{l}0.495 \\
(0.25)\end{array}$ & $0.441 * *$ & $\begin{array}{l}0.771 \\
(0.26)\end{array}$ & $\begin{array}{l}0.300 \\
(0.19)\end{array}$ & $0.471^{* *}$ \\
\hline$N$ & 108,763 & $2,440,366$ & & 137,233 & $2,919,558$ & \\
\hline
\end{tabular}

a Age - years of schooling - 6. Based on full-time full-year non-military employees with no self-employment income.

${ }^{* *} p<0.01$.

${ }^{*} p<0.05$ 
Table 2. Disability and Wage Regressions

\section{Dep. Var. = ln(hourly earnings)}

\section{Women}

\section{Men}
(1)
(2)
(3)
(4)
(5)
(6)
(7)
(8)

$\begin{array}{lll}\text { Any disability } & -0.161 * * & -0.123 * * \\ (0.002) & (0.002)\end{array}$

$-0.190 * *-0.172 * *$

(0.004) (0.004)

Disability type

Visual

impairment

Hearing

impairment

Cognitive

impairment

Mobility

impairment

Otherwise

limited in

daily

activities

$$
\begin{array}{ll}
-0.085 * * & -0.064 * * \\
(0.004) & (0.004) \\
-0.045^{* *} & -0.028^{* *} \\
(0.004) & (0.003) \\
-0.182 * * & -0.135^{* *} \\
(0.005) & (0.004) \\
-0.137 * * & -0.108 * * \\
(0.003) & (0.003) \\
& \\
-0.144 * * & -0.112 * * \\
(0.009) & (0.008)
\end{array}
$$

$$
\begin{array}{ll}
-0.115^{* *} & -0.094 * * \\
(0.005) & (0.004) \\
-0.046^{* *} & -0.038^{* *} \\
(0.003) & (0.003) \\
-0.246^{* *} & -0.217^{* *} \\
(0.006) & (0.006) \\
-0.193 * * & -0.185^{* *} \\
(0.005) & (0.005) \\
& \\
-0.187 * * & -0.174 * * \\
(0.010) & (0.009)
\end{array}
$$

Education

$\begin{array}{lllllllll}\text { Some high } & 0.143^{* *} & 0.080^{* *} & 0.143^{* *} & 0.080^{* *} & 0.142^{* *} & 0.087 * * & 0.138^{* *} & 0.083^{* *} \\ \text { school } & (0.004) & (0.003) & (0.004) & (0.003) & (0.003) & (0.003) & (0.003) & (0.003) \\ \text { High } & 0.417^{* *} & 0.242^{* *} & 0.416^{* *} & 0.241^{* *} & 0.363^{* *} & 0.258^{* *} & 0.362^{* *} & 0.258^{* *} \\ \text { school grad } & (0.003) & (0.003) & (0.003) & (0.003) & (0.002) & (0.002) & (0.002) & (0.002) \\ \text { GED } & 0.353^{* *} & 0.199^{* *} & 0.353^{* *} & 0.199^{* *} & 0.292^{* *} & 0.191^{* *} & 0.289^{* *} & 0.189^{* *} \\ & (0.004) & (0.004) & (0.004) & (0.004) & (0.003) & (0.003) & (0.003) & (0.003) \\ \text { Some } & 0.612^{* *} & 0.347^{* *} & 0.610^{* *} & 0.346^{* *} & 0.554^{* *} & 0.368^{* *} & 0.554^{* *} & 0.369 * * \\ \text { college, no } & (0.003) & (0.003) & (0.003) & (0.003) & (0.003) & (0.003) & (0.003) & (0.003) \\ \text { degree } & & & & & & & & \\ \text { AA degree } & 0.741^{* *} & 0.377^{* *} & 0.739^{* *} & 0.376^{* *} & 0.622^{* *} & 0.394^{* *} & 0.623^{* *} & 0.395^{* *} \\ & (0.004) & (0.004) & (0.004) & (0.004) & (0.003) & (0.003) & (0.003) & (0.003) \\ \text { BA degree } & 1.005^{* *} & 0.583^{* *} & 1.003^{* *} & 0.582^{* *} & 0.944^{* *} & 0.598^{* *} & 0.946^{* *} & 0.600^{* *} \\ & (0.004) & (0.004) & (0.004) & (0.004) & (0.003) & (0.003) & (0.003) & (0.003) \\ \text { Master's } & 1.183^{* *} & 0.772^{* *} & 1.182^{* *} & 0.770^{* *} & 1.145^{* *} & 0.776^{* *} & 1.148^{* *} & 0.777^{* *} \\ \text { degree } & (0.004) & (0.004) & (0.004) & (0.004) & (0.003) & (0.003) & (0.003) & (0.003) \\ \text { Professiona } & 1.473^{* *} & 0.828^{* *} & 1.471^{* *} & 0.827^{* *} & 1.421^{* *} & 0.844^{* *} & 1.424^{* *} & 0.847 * * \\ \text { l degree } & (0.005) & (0.005) & (0.005) & (0.005) & (0.005) & (0.005) & (0.005) & (0.005) \\ \text { PhD } & 1.421^{* *} & 0.929 * * & 1.419 * * & 0.927 * * & 1.271^{* *} & 0.929 * * & 1.275^{* *} & 0.932^{* *} \\ & (0.005) & (0.005) & (0.005) & (0.005) & (0.005) & (0.005) & (0.005) & (0.005)\end{array}$

Race and ethnicity

$$
\begin{array}{llllllllll} 
& -0.090^{* *}-0.036^{* *}-0.090^{* *}-0.036^{* *}-0.235^{* *}-0.145^{* *} & -0.237^{* *}-0.146^{* *} \\
\text { Black } & (0.001) & (0.001) & (0.001) & (0.001) & (0.002) & (0.002) & (0.002) & (0.002)
\end{array}
$$




\begin{tabular}{|c|c|c|c|c|c|c|c|c|}
\hline $\begin{array}{l}\text { Native } \\
\text { American }\end{array}$ & $\begin{array}{l}-0.100 * * \\
(0.005)\end{array}$ & $\begin{array}{l}-0.056^{* *} \\
(0.004)\end{array}$ & $\begin{array}{l}-0.100 * * \\
(0.005)\end{array}$ & $\begin{array}{l}-0.056^{* *} \\
(0.004)\end{array}$ & $\begin{array}{l}-0.164 * * \\
(0.005)\end{array}$ & $\begin{array}{l}0.129 * *(0.005 \\
)\end{array}$ & $\begin{array}{l}-0.167 * * \\
(0.005)\end{array}$ & $\begin{array}{l}-0.133^{* *} \\
(0.005)\end{array}$ \\
\hline Asian & $\begin{array}{l}-0.065^{* *} \\
(0.002)\end{array}$ & $\begin{array}{l}-0.058^{* *} \\
(0.002)\end{array}$ & $\begin{array}{l}-0.064 * * \\
(0.002)\end{array}$ & $\begin{array}{l}-0.058^{* *} \\
(0.002)\end{array}$ & $\begin{array}{l}-0.120^{* *} \\
(0.002)\end{array}$ & $\begin{array}{l}-0.113^{* *} \\
(0.002)\end{array}$ & $\begin{array}{l}-0.121^{* *} \\
(0.002)\end{array}$ & $\begin{array}{l}-0.114^{* *} \\
(0.002)\end{array}$ \\
\hline Other race & $\begin{array}{l}-0.049^{* *} \\
(0.002)\end{array}$ & $\begin{array}{l}-0.030^{* *} \\
(0.002)\end{array}$ & $\begin{array}{l}-0.048^{* *} \\
(0.002)\end{array}$ & $\begin{array}{l}-0.030^{* *} \\
(0.002)\end{array}$ & $\begin{array}{l}-0.075^{* *} \\
(0.002)\end{array}$ & $\begin{array}{l}-0.052 * * \\
(0.002)\end{array}$ & $\begin{array}{l}-0.075^{* *} \\
(0.002)\end{array}$ & $\begin{array}{l}-0.052 * * \\
(0.002)\end{array}$ \\
\hline Hispanic & $\begin{array}{l}-0.147^{* *} \\
(0.001)\end{array}$ & $\begin{array}{l}-0.087 * * \\
(0.001)\end{array}$ & $\begin{array}{l}-0.148^{* *} \\
(0.001)\end{array}$ & $\begin{array}{l}-0.087 * * \\
(0.001)\end{array}$ & $\begin{array}{l}-0.187 * * \\
(0.001)\end{array}$ & $\begin{array}{l}-0.110^{* *} \\
(0.001)\end{array}$ & $\begin{array}{l}-0.186^{* *} \\
(0.001)\end{array}$ & $\begin{array}{l}-0.109 * * \\
(0.001)\end{array}$ \\
\hline $\begin{array}{l}58 \text { labour mkt } \\
\text { experience } \\
\text { dummies }\end{array}$ & Yes & Yes & Yes & Yes & Yes & Yes & Yes & Yes \\
\hline $\begin{array}{l}\text { Five-year } \\
\text { dummies }\end{array}$ & Yes & Yes & Yes & Yes & Yes & Yes & Yes & Yes \\
\hline $\begin{array}{l}49 \text { state } \\
\text { dummies }\end{array}$ & Yes & Yes & Yes & Yes & Yes & Yes & Yes & Yes \\
\hline $\begin{array}{l}524 \text { occupation } \\
\text { dummies }\end{array}$ & No & Yes & No & Yes & No & Yes & No & Yes \\
\hline $\begin{array}{l}\text { Inverse Mill's } \\
\text { ratio }\end{array}$ & $\begin{array}{l}0.134^{* *} \\
(0.003)\end{array}$ & $\begin{array}{l}0.109 * * \\
(0.002)\end{array}$ & $\begin{array}{l}0.134^{* *} \\
(0.003)\end{array}$ & $\begin{array}{l}0.109 * * \\
(0.002)\end{array}$ & $\begin{array}{l}0.154^{* *} \\
(0.007)\end{array}$ & $\begin{array}{l}0.173^{* *} \\
(0.007)\end{array}$ & $\begin{array}{l}0.174 * * \\
(0.007)\end{array}$ & $\begin{array}{l}0.191^{* *} \\
(0.007)\end{array}$ \\
\hline Observations & $\begin{array}{l}2,549,12 \\
9\end{array}$ & $\begin{array}{l}2,549,12 \\
9\end{array}$ & $\begin{array}{l}2,549,12 \\
9\end{array}$ & $\begin{array}{l}2,549,12 \\
9\end{array}$ & $\begin{array}{l}3,056,79 \\
1\end{array}$ & $3,056,791$ & $\begin{array}{l}3,056,79 \\
1\end{array}$ & $\begin{array}{l}3,056,79 \\
1\end{array}$ \\
\hline$R$-squared & 0.347 & 0.482 & 0.347 & 0.482 & 0.372 & 0.481 & 0.372 & 0.481 \\
\hline
\end{tabular}

Robust standard errors in parentheses.

${ }^{* *} p<0.01$.

${ }^{*} p<0.05$. 
Table 3. Descriptive Statistics on Occupational Job Requirements

Correlation with \% of employees with given impairment in occup.a

\section{Job requirements measureb}

Women

1. Visual reqs. index

2. Very important visual req.

3. Hearing reqs. index

4. Very important hearing req.

5. Cognitive reqs. index

6. Very important cognitive req.

7. Mobility reqs. index

8. Very important mobility req. Men

1. Visual reqs. index

2. Very important visual req.

3. Hearing reqs. index

4. Very important hearing req.

5. Cognitive reqs. index

6. Very important cognitive req.

7. Mobility reqs. index

8. Very important mobility req.

$N$ Women

Men
(1)

$$
\begin{aligned}
& -0.570^{* *} \\
& -0.399^{* *} \\
& -0.536^{* *} \\
& -0.429^{* *} \\
& -0.745^{* *} \\
& -0.517^{* *} \\
& 0.354^{* *} \\
& -0.008^{* *}
\end{aligned}
$$

$-0.507 * *$

$-0.446 * *$

$-0.538^{* *}$

$-0.383 * *$

$-0.767 * *$

$-0.552 * *$

$0.406 * *$

0.085

524

524

\section{Descriptive statistics}

Mean (s.d.) Minimum Median Maximum
(2)
(3)
(4)
(6)

(8)

$\begin{array}{llll}0.156 & (0.024) 0.082 & 0.158 & 0.271 \\ 0.285 & (0.379) 0.000 & 0.154 & 1.000 \\ 0.150 & (0.030) 0.067 & 0.153 & 0.219 \\ 0.577 & (0.483) 0.000 & 1.000 & 1.000 \\ 0.331 & (0.058) 0.186 & 0.330 & 0.558 \\ 0.624 & (0.481) 0.000 & 1.000 & 1.000 \\ 0.045 & (0.032) 0.010 & 0.030 & 0.196 \\ 0.022 & (0.057) 0.000 & 0.000 & 1.000\end{array}$

0.165

(0.026) 0.082

$0.166 \quad 0.271$

0.243

(0.363) 0.000

$0.000 \quad 1.000$

0.136

(0.033) 0.067

$0.133 \quad 0.219$

0.411

(0.473) 0.000

$0.000 \quad 1.000$

0.317

(0.065) 0.186

$0.305 \quad 0.558$

0.476

(0.489) 0.000

$0.000 \quad 1.000$

0.068

(0.043) 0.010

$0.067 \quad 0.196$

0.037

$0.145 \quad 0.000$

0.000

1.000

3,056,791

a Correlations are at occupation level — for example, the occupation's visual requirements index is negatively correlated with the percentage of employees in the occupation who have visual impairments.

b Measures 1, 3, 5 and 7 are based on proportion of occupation's required abilities limited by given impairment, weighted by importance. Measures 2, 4, 6 and 8 are based on the likelihood that at least one very important ability in an occupation is limited by given impairment. See text for calculation of scores.

$$
\begin{aligned}
& { }^{* *} p<0.01 . \\
& { }^{*} p<0.05 .
\end{aligned}
$$


Table 4. Disability Pay Gaps and Job Requirements

Dep. Var. = ln(hourly earnings).

Women

\section{Row}

Row (1)

1 Visual impairment

2 * visual reqs. index

3 * very important visual req.

4 Hearing impairment

5

$$
\text { * hearing reqs. }
$$

index

* very important

hearing req.

7 Cognitive impairment

* cognitive reqs. index

9 * very important cognitive req.

10 Mobility impairment

$11 *$ mobility reqs. index

12 * very important mobility req.

$N$

$R$-squared

(2) $-0.064 * *$
$(0.005)$

$-0.034$

(0.028)

$-0.199$

(0.181)

$$
-0.028 * * \quad 0.030
$$$$
\text { (0.004) }
$$

(0.016)

$-0.395^{* *}$

(0.109)

(0.069)

$-0.121 * *$

(0.008)

$0.269 *$

(0.120)

$2,549,129$
0.482

$$
\begin{gathered}
-0.023 \\
(0.014)
\end{gathered}
$$

$$
-0.021^{* *}
$$

(0.005)

\section{(3)}

(4)

Men

\section{(5)}

(6)

$(0.006) \quad-0.094 *$

(0.005)

-0.130 **

(0.029)

0.226

(0.180)

$\begin{array}{ll} & -0.021 \\ & (0.013) \\ 0.023 & -0.031^{* *} \\ (0.017) & (0.005) \\ -0.471^{* *} & \\ (0.134) & \\ & -0.021^{*} \\ & (0.010) \\ -0.182^{* *} & -0.207^{* *} \\ (0.034) & (0.020) \\ -0.115 & \\ (0.080) & \end{array}$

$$
-0.012
$$

(0.007)

$$
-0.038^{* *}
$$

(0.004)

$-0.026^{*}$

$(0.011)$

$$
(0.010)
$$

$-0.108^{* *}$

(0.008)

$-0.185^{* *}$

$(0.017)$

$-0.210 * *$

(0.018)

$-0.185^{* *}$

$0.356 * *$

(0.116)

(0.017)
0.002

(0.072)

2,549,129

0.482
$2,549,129$

0.482

$\begin{array}{ll} & 0.007 \\ & (0.021) \\ 3,056,791 & 3,056,791 \\ 0.481 & 0.481\end{array}$

All regressions include independent variables from Table 2, columns 4 and 8. Robust standard errors in parentheses.

${ }^{* *} p<0.01$.

${ }^{*} p<0.05$. 
Table 5. Disability Pay Gaps Along the Job Requirements Spectrum

Dep. Var. = ln(wage). Regressions run separately by whether job requirement is very important in employee's occupation

Women

Men

(1)

(2)

(3)

(4)

Very important visual req.

$\begin{array}{lllll} & \text { No } & \text { Yes } & \text { No } & \text { Yes } \\ \text { Visual impairment coeff. } & -0.073 * * & -0.090 * * & -0.095 * * & -0.131 * * \\ n & (0.006) & (0.009) & (0.006) & (0.021) \\ & 1,109,018 & 692,401 & 1,550,057 & 712,787 \\ & \text { Very important hearing req. } & & \\ \text { Hearing impairment coeff. } & \text { No } & \text { Yes } & \text { No } & \text { Yes } \\ & -0.039 * * & -0.043 * * & -0.032 * * & -0.057 * * \\ n & (0.006) & (0.006) & (0.004) & (0.005) \\ & 940,596 & 1,451,827 & 1,525,000 & 1,215,635 \\ & \text { Very important cognitive req. } & & \\ \text { Cognitive impairment coeff. } & \text { No } & \text { Yes } & \text { No } & \text { Yes } \\ & -0.140 * * & -0.194 * * & -0.192 * * & -0.211 * * \\ n & (0.007) & (0.006) & (0.008) & (0.010) \\ & 916,375 & 1,619,761 & 1,505,485 & 1,543,784 \\ & \text { Very important mobility req. } & & \\ \text { Mobility impairment coeff. } & \text { No } & \text { Yes } & \text { No } & \text { Yes } \\ & -0.136 * * & -0.023 & -0.185 * * & -0.183 * * \\ & (0.004) & (0.026) & (0.006) & (0.030) \\ & 1,930,339 & 7,084 & 2,507,463 & 91,969\end{array}$

All regressions contain occupation fixed effects and other independent variables from Table 2, columns 4 and 8.

Robust standard errors in parentheses.

${ }^{* *} p<0.01$.

${ }^{*} p<0.05$. 
Table 6. Occupation-Level Regressions of Pay Gaps on Job Requirements

Dep. Var. = occupation-level pay gap associated with impairment, controlling for variables in Table 3, columns 4 and 8

Women Men

Indep. Vars.

(1)

(2)

(3)

(4)

Panel A

Dep. Var.:

Visual impairment pay gap

Constant (requirements-adjusted gap)

$$
-0.008
$$$$
-0.006^{* *}
$$

$-0.090 * *$

$$
\text { (0.027) }
$$

$$
\text { (0.005) }
$$

(0.027)

(0.005)

Visual reqs. index

$$
-0.372 *
$$

(0.176)

Very important vision req.

$\begin{array}{llll} & -0.025^{*} & & -0.019 \\ 309 & (0.012) & & (0.013) \\ 309 & 423 & 423\end{array}$

Panel B

Dep. Var.:

Hearing impairment pay gap

Constant (requirements-adjusted gap)

$$
\begin{aligned}
& 0.039 * \\
& (0.016)
\end{aligned}
$$$$
-0.019 * *
$$$$
\text { (0.005) }
$$

Hearing reqs. index

$-0.459 * *$

$-0.515^{* *}$

(0.111)

(0.092)

Very important hearing req.

$n$

Panel C

Dep. Var.:

Constant (requirements-adjusted gap)

Cognitive reqs. index

Very important cognitive req.

$n$

PANEL D

Dep. Var.:

Constant (requirements-adjusted gap)

Mobility reqs. index

$\begin{array}{llll} & -0.018^{*} & & -0.024 * * \\ & (0.007) & & (0.006) \\ 331 & 331 & 473 & 473\end{array}$

Cognitive impairment pay gap

$\begin{array}{llll}-0.011 & -0.114 * * & -0.168^{* *} & -0.207^{* *} \\ (0.024) & (0.006) & (0.020) & (0.005)\end{array}$

$-0.399 * *$

$-0.164 * *$

(0.077)

(0.066)

$\begin{array}{llll} & -0.044^{* *} & & -0.027 \\ & (0.009) & & (0.009)^{*} \\ 324 & 324 & 418 & 418\end{array}$

Mobility impairment pay gap
$-0.123 * *$
$-0.107 * *$
$-0.214 * *$
(0.006)
(0.004)
(0.008)
$0.298 * *$
$0.397 * *$
(0.100) (0.090)

$-0.186^{* *}$ 
Dep. Var. = occupation-level pay gap associated with impairment, controlling for variables in Table 3, columns 4 and 8

\section{Indep. Vars.}

Very important mobility req.

$n$

\section{Women}

(1)

(2) $-0.059$

(0.067)
Men

(3)

Standard errors in parentheses.

All regressions restricted to occupations with five or more employees with given impairment, weighted by number of employees with impairment.

${ }^{* *} p<0.01$.

${ }^{*} p<0.05$. 


\section{Figure Legends}

1. (a) Visual Impairment Pay Gaps and Job Requirements- Women; (b) Visual Impairment Pay Gaps and Job Requirements- Men.

2. (a) Hearing Impairment Pay Gaps and Job Requirements— Women; (b) Hearing Impairment Pay Gaps and Job Requirements— Men.

3. (a) Cognitive Impairment Pay Gaps and Job Requirements- Women; (b) Cognitive Impairment Pay Gaps and Job Requirements- Men.

4. (a) Mobility Impairment Pay Gaps and Job Requirements — Women; (b) Mobility Impairment Pay Gaps and Job Requirements— Men.

5. (a) Visual Job Requirements and Pay Gaps - Women; (b) Visual Job Requirements and Pay Gaps- Men.

6. (a) Hearing Job Requirements and Pay Gaps_-Women; (b) Hearing Job Requirements and Pay Gaps— Men.

7. (a) Cognitive Job Requirements and Pay Gaps— Women; (b) Cognitive Job Requirements and Pay Gaps —Men.

8. (a) Mobility Job Requirements and Pay— Women; (b) Mobility Job Requirements and Pay Gaps- Men. 


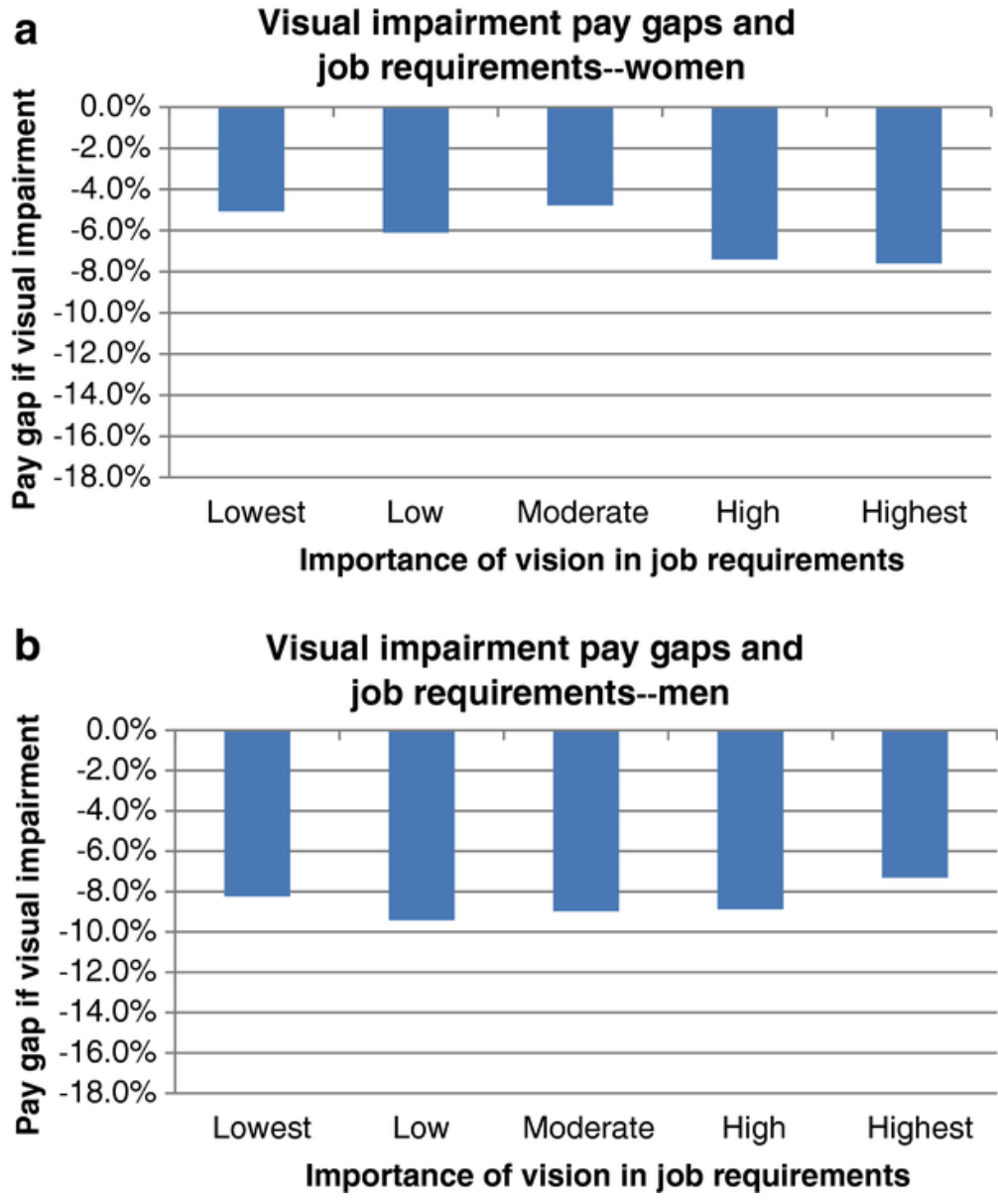

Figure 1 


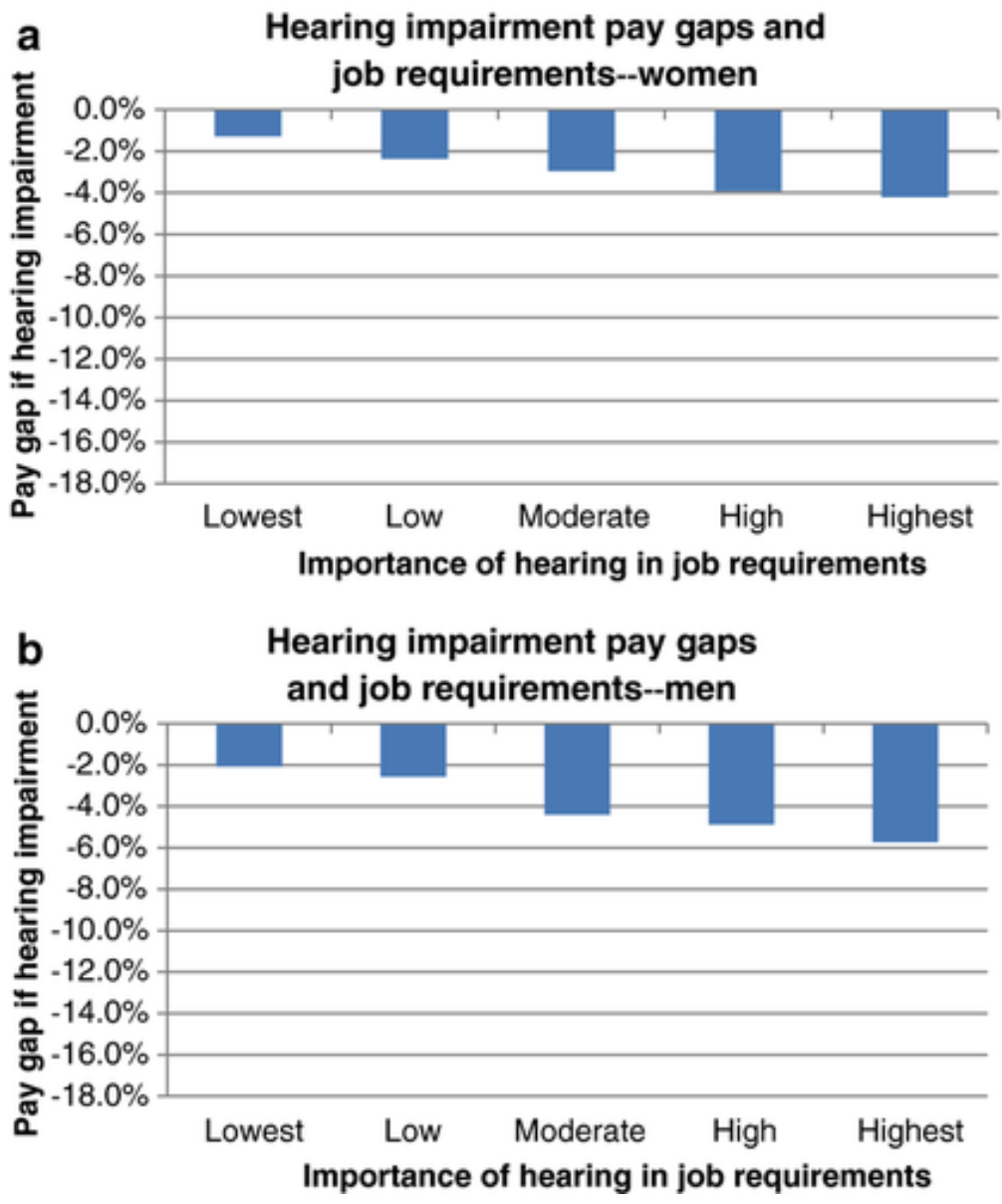

Figure 2 

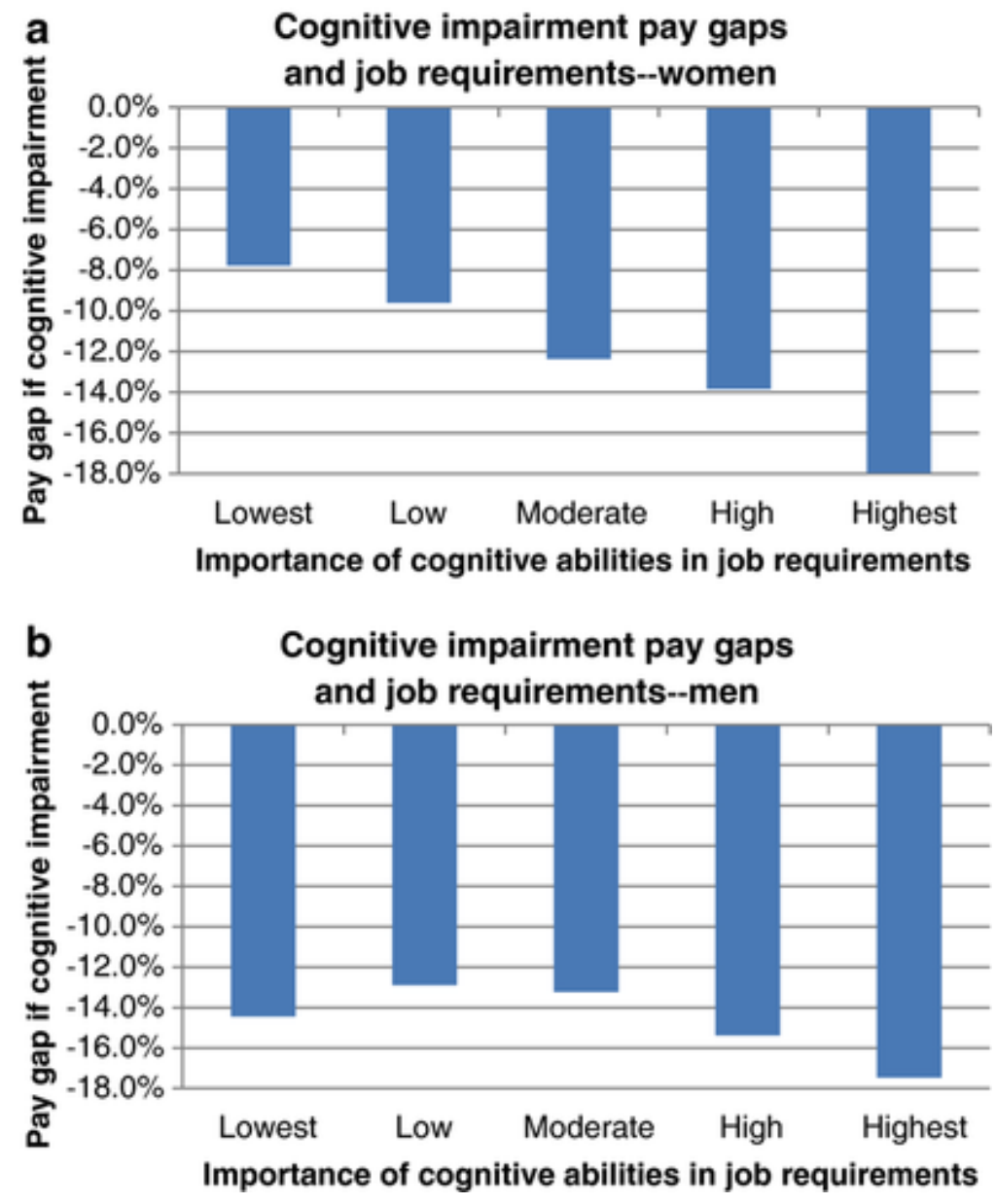

Figure 3 

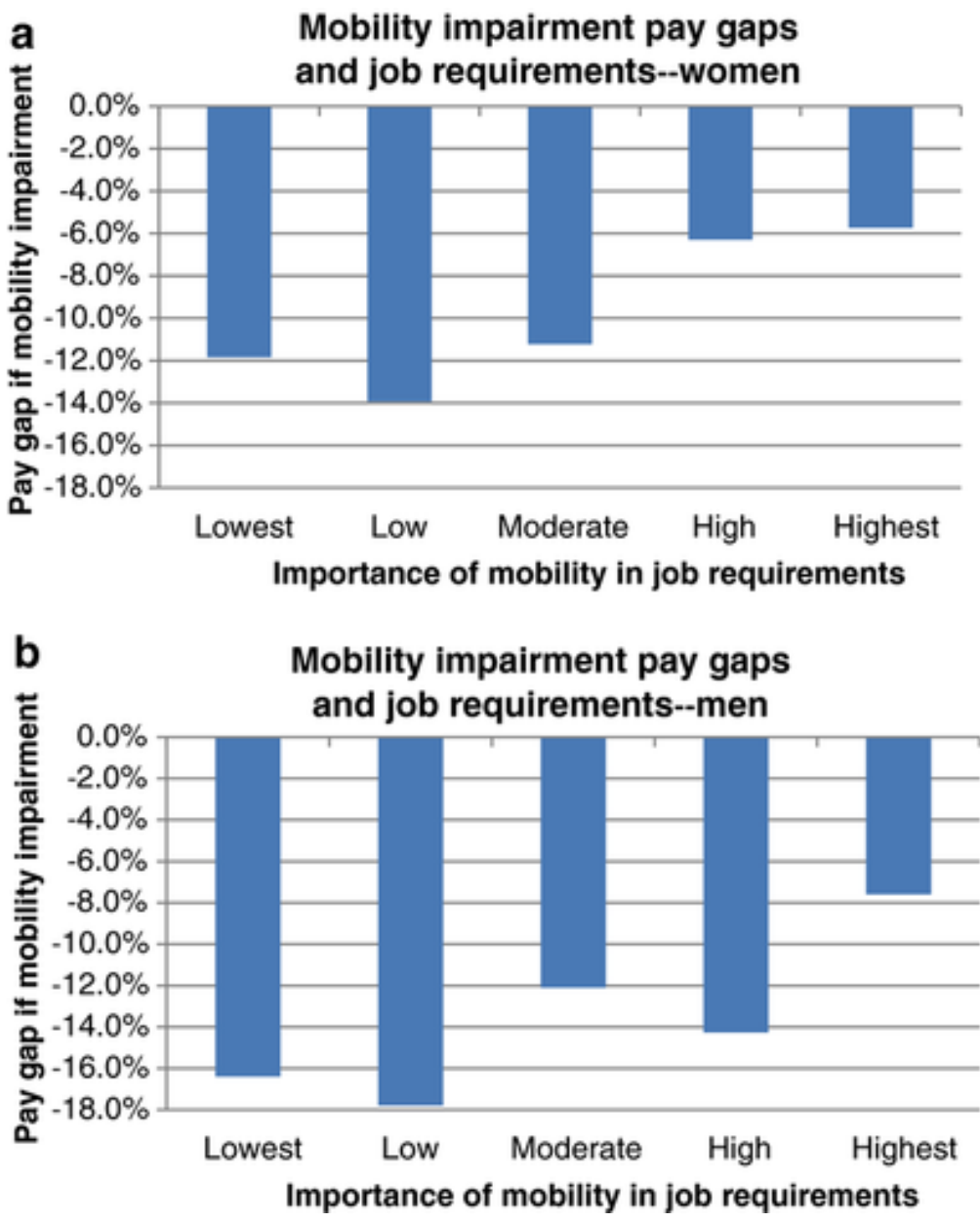

Figure 4 

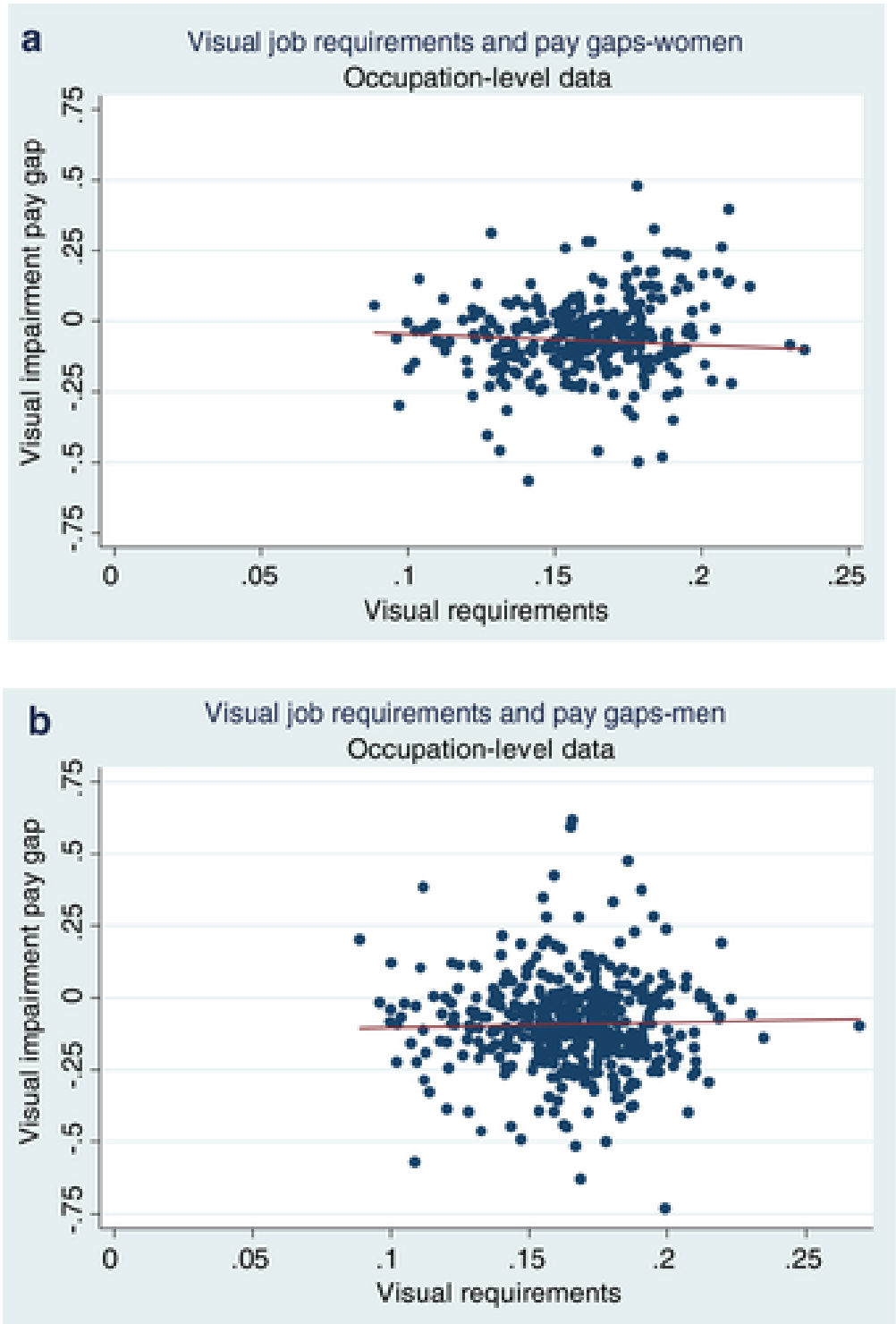

Figure 5 

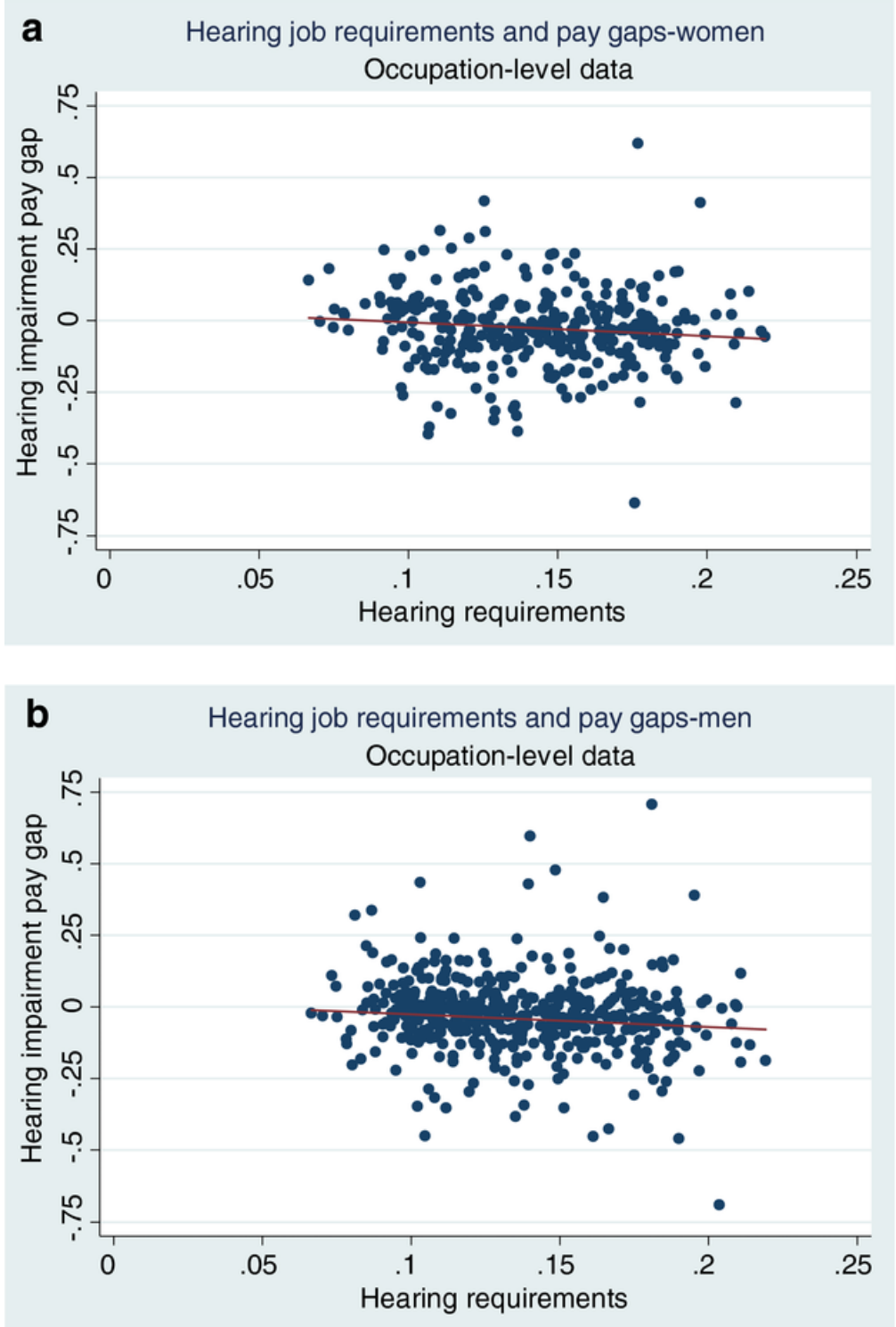

Figura 6 

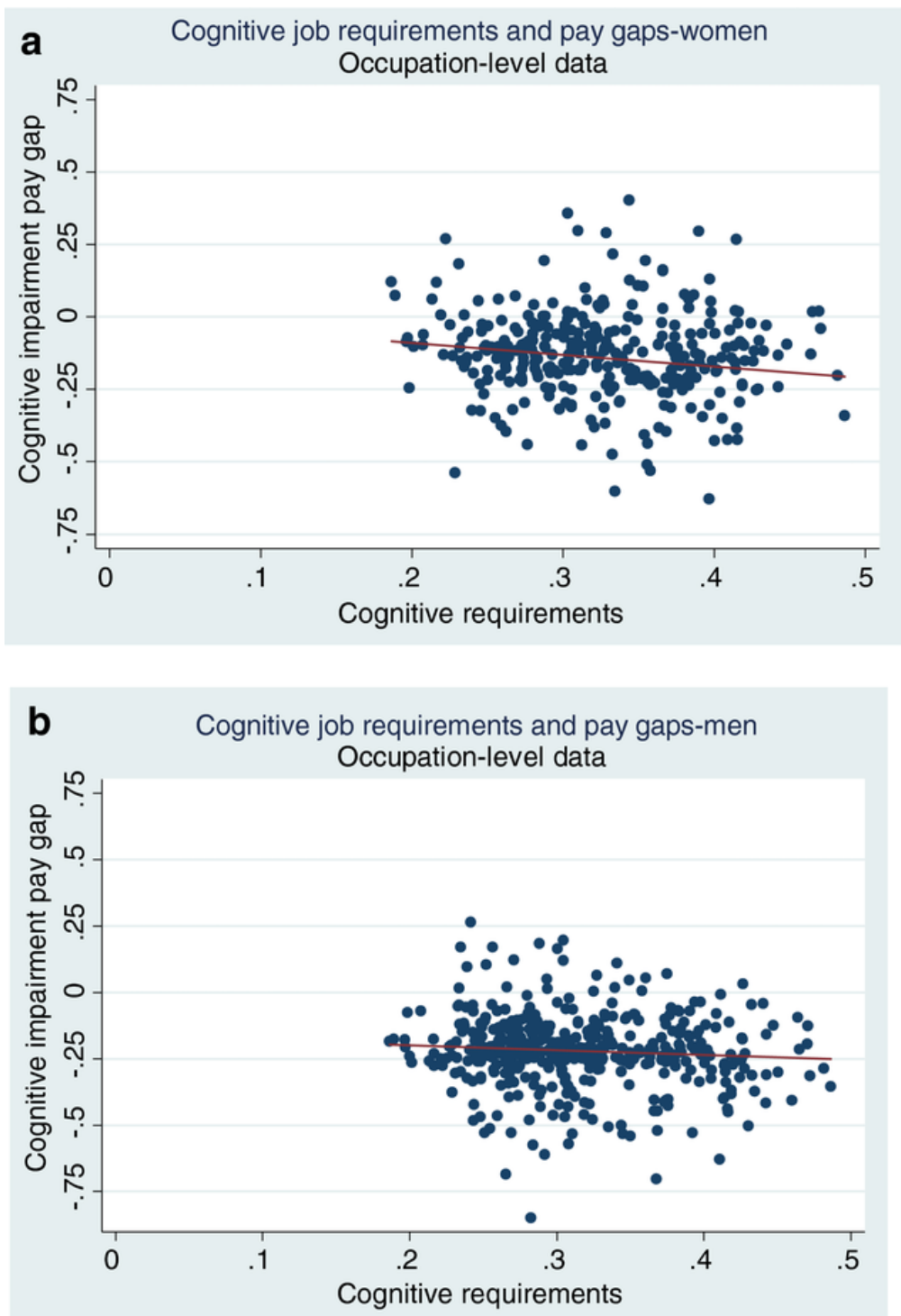

Figure 7 

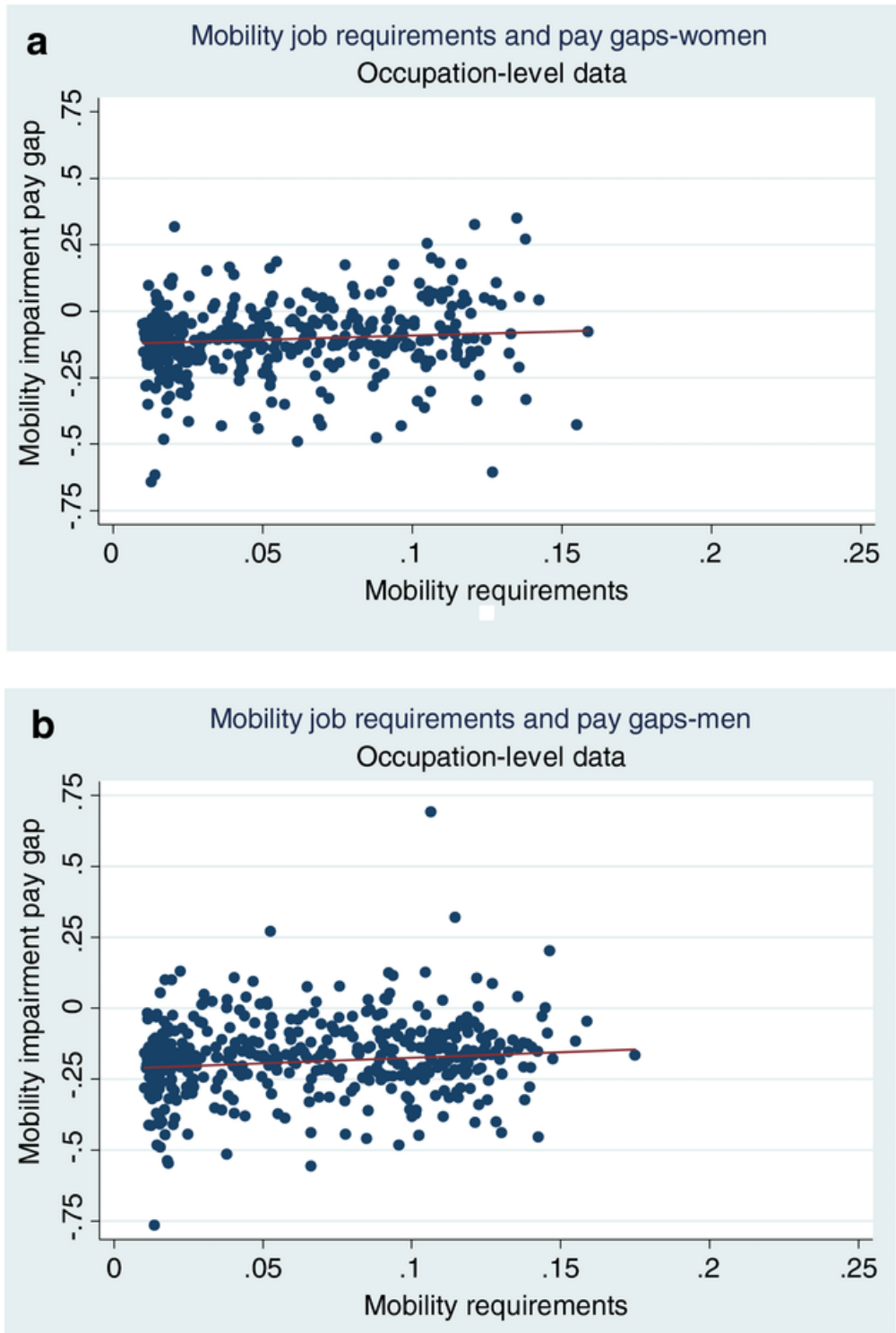

Figure 8 
Appendix A. Questions Used by Census Bureau to Identify Disability Status on ACS (http://www.census.gov/people/disability/methodology/)

1. 'Is this person deaf or does he/she have serious difficulty hearing?'

2. 'Is this person blind or does he/she have serious difficulty seeing even when wearing glasses?'

3. 'Because of a physical, mental or emotional condition, does this person have serious difficulty concentrating, remembering or making decisions?’

4. 'Does this person have serious difficulty walking or climbing stairs?'

5. 'Does this person have difficulty dressing or bathing?'

6. 'Because of a physical, mental or emotional condition, does this person have difficulty doing errands alone such as visiting a doctor's office or shopping? 


\section{Appendix B. Information on abilities from O*Net}

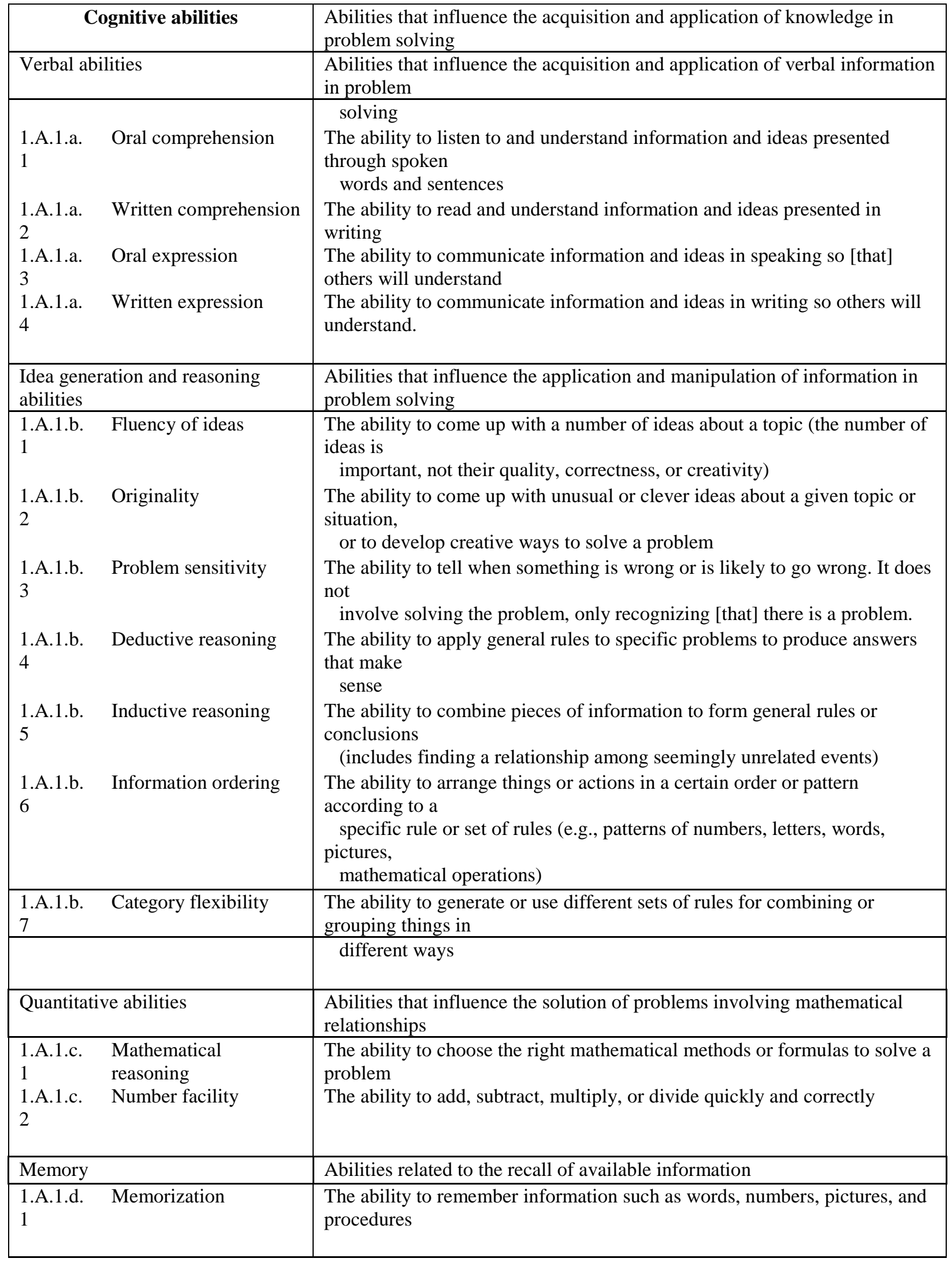




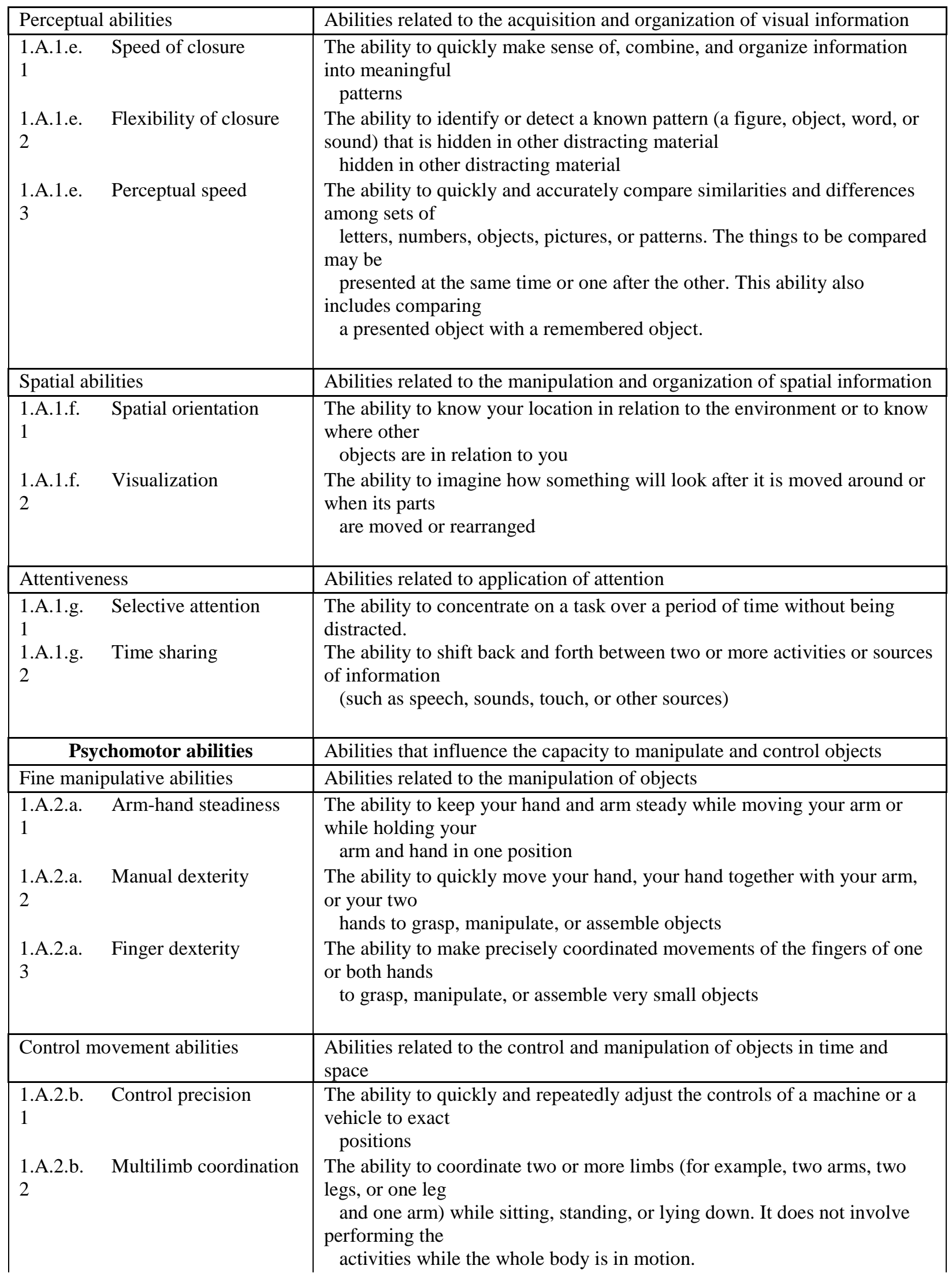




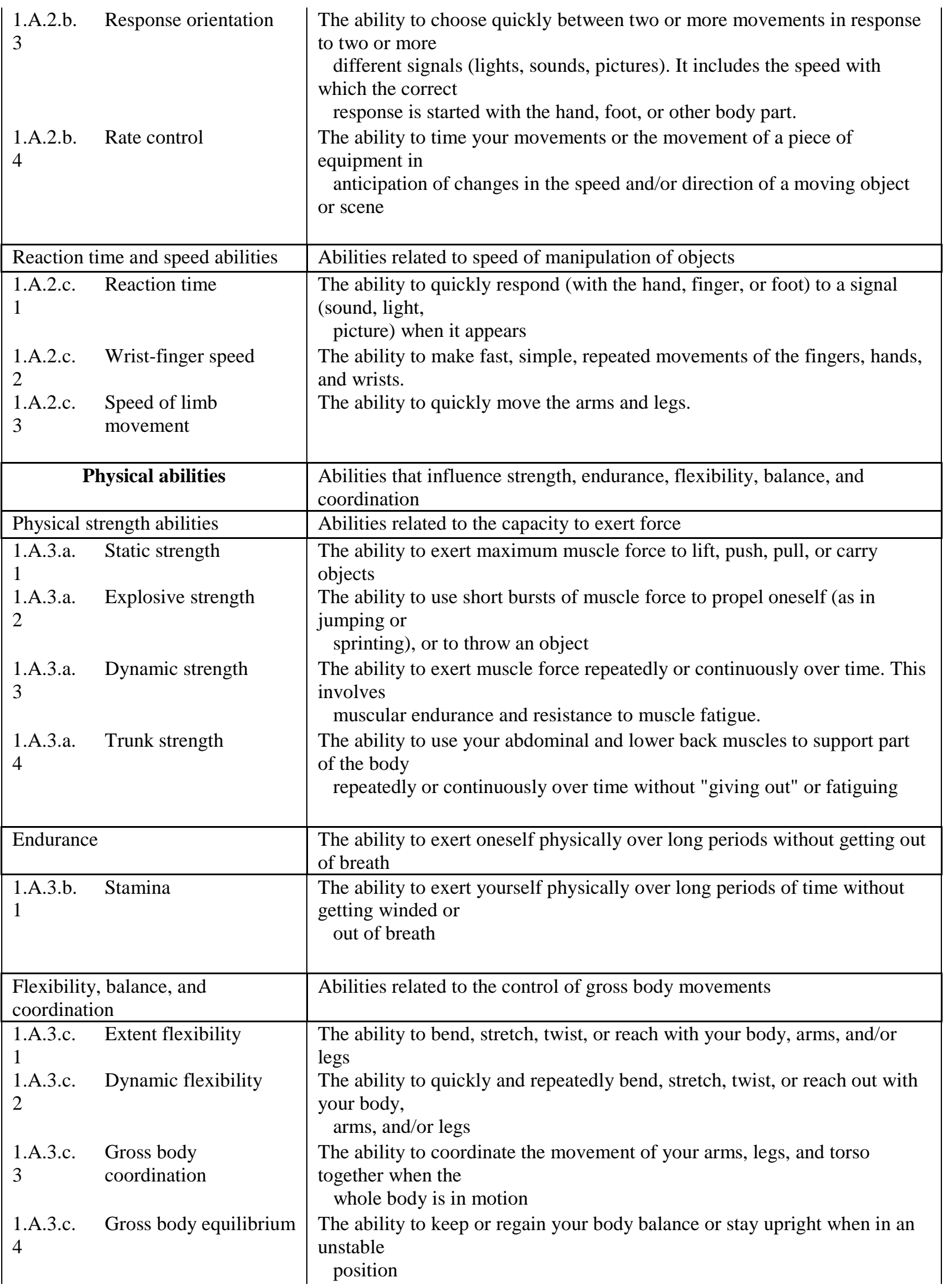




\begin{tabular}{|c|c|c|}
\hline \multicolumn{2}{|c|}{ Sensory abilities } & Abilities that influence visual, auditory, and speech perception \\
\hline \multicolumn{2}{|c|}{ Visual abilities } & Abilities related to visual sensory input \\
\hline $\begin{array}{l}\text { 1.A.4.a. } \\
1\end{array}$ & Near vision & The ability to see details at close range (within a few feet of the observer) \\
\hline $\begin{array}{l}\text { 1.A.4.a. } \\
2\end{array}$ & Far vision & The ability to see details at a distance \\
\hline $\begin{array}{l}\text { 1.A.4.a. } \\
3\end{array}$ & $\begin{array}{l}\text { Visual color } \\
\text { discrimination }\end{array}$ & $\begin{array}{l}\text { The ability to match or detect differences between colors, including shades } \\
\text { of color and } \\
\text { brightness }\end{array}$ \\
\hline $\begin{array}{l}\text { 1.A.4.a. } \\
4\end{array}$ & Night vision & The ability to see under low light conditions \\
\hline $\begin{array}{l}\text { 1.A.4.a. } \\
5\end{array}$ & Peripheral vision & $\begin{array}{l}\text { The ability to see objects or movement of objects to one's side when the } \\
\text { eyes are looking } \\
\text { ahead }\end{array}$ \\
\hline $\begin{array}{l}\text { 1.A.4.a. } \\
6\end{array}$ & Depth perception & $\begin{array}{l}\text { The ability to judge which of several objects is closer or farther away from } \\
\text { you, or to judge } \\
\text { the distance between you and an object }\end{array}$ \\
\hline $\begin{array}{l}\text { 1.A.4.a. } \\
7\end{array}$ & Glare sensitivity & The ability to see objects in the presence of glare or bright lighting \\
\hline \multicolumn{2}{|c|}{ Auditory and speech abilities } & Abilities related to auditory and oral input \\
\hline $\begin{array}{l}\text { 1.A.4.b. } \\
1\end{array}$ & Hearing sensitivity & $\begin{array}{l}\text { The ability to detect or tell the differences between sounds that vary in pitch } \\
\text { and } \\
\text { loudness }\end{array}$ \\
\hline $\begin{array}{l}\text { 1.A.4.b. } \\
2\end{array}$ & Auditory attention & $\begin{array}{l}\text { The ability to focus on a single source of sound in the presence of other } \\
\text { distracting } \\
\text { sounds }\end{array}$ \\
\hline $\begin{array}{l}\text { 1.A.4.b. } \\
3\end{array}$ & Sound localization & The ability to tell the direction from which a sound originated \\
\hline $\begin{array}{l}\text { 1.A.4.b. } \\
4\end{array}$ & Speech recognition & The ability to identify and understand the speech of another person \\
\hline $\begin{array}{l}\text { 1.A.4.b. } \\
5\end{array}$ & Speech clarity & The ability to speak clearly so [that] others can understand you \\
\hline
\end{tabular}

